\title{
WestVirginiaUniversity
}

THE RESEARCH REPOSITORY @ WVU

Graduate Theses, Dissertations, and Problem Reports

2021

\section{Understanding Visitor Use at Florida Keys National Marine Sanctuary}

Melissa Maria Hurtado Alvarez

West Virginia University, mmh00001@mix.wvu.edu

Follow this and additional works at: https://researchrepository.wvu.edu/etd

Part of the Natural Resources Management and Policy Commons, Recreation, Parks and Tourism Administration Commons, and the Tourism Commons

\section{Recommended Citation}

Hurtado Alvarez, Melissa Maria, "Understanding Visitor Use at Florida Keys National Marine Sanctuary" (2021). Graduate Theses, Dissertations, and Problem Reports. 10261.

https://researchrepository.wvu.edu/etd/10261

This Thesis is protected by copyright and/or related rights. It has been brought to you by the The Research Repository @ WVU with permission from the rights-holder(s). You are free to use this Thesis in any way that is permitted by the copyright and related rights legislation that applies to your use. For other uses you must obtain permission from the rights-holder(s) directly, unless additional rights are indicated by a Creative Commons license in the record and/ or on the work itself. This Thesis has been accepted for inclusion in WVU Graduate Theses, Dissertations, and Problem Reports collection by an authorized administrator of The Research Repository @ WVU. For more information, please contact researchrepository@mail.wvu.edu. 


\title{
Understanding Visitor Use at Florida Keys National Marine Sanctuary
}

\author{
Melissa Maria Hurtado Alvarez
}

Thesis submitted to the Davis College of Natural Resources at West Virginia University in partial fulfillment of the requirements for the degree of Master of Science in Recreation, Parks, and Tourism Resources

\author{
Robert Burns, Ph.D., Chair \\ Jasmine Moreira, Ph.D. \\ Michael Strager, Ph.D. \\ David Smaldone, Ph.D.
}

Recreation, Parks, and Tourism Resources

Morgantown, West Virginia

2021

Keywords: Visitor Use; Marine Protected Areas; Tourism; Florida Keys; Satisfaction; Crowding;

Importance Performance Analysis; Recreation Management.

Copyright 2021 Melissa Maria Hurtado Alvarez 


\title{
Abstract \\ Understanding Visitor Use at Florida Keys National Marine Sanctuary
}

\author{
Melissa Maria Hurtado Alvarez
}

Effective management and monitoring of visitor recreational use is fundamental in marine protected areas. It is common to hear that tourism and outdoor recreation are often qualified as double-edged activities, making valuable socioeconomic contributions but also causing degradation of the environment. The convergence of social and natural resource research and practices can help managers to create better policies that will maximize human benefits from, and minimize human pressures on, ocean and coastal environments. For this study online surveys were sent via Qualtrics to email addresses obtained from the state of Florida during the summer of 2020. The first paper assessed user satisfaction and crowding at Florida Keys National Marine Sanctuary. The results of the first paper showed that respondents felt very satisfied and only slightly crowded while snorkeling or scuba diving. An ANOVA showed that satisfaction levels were significantly lower in users who saw more people than they expected. The second paper examined an Importance-Performance Analysis (IPA) of recreationists (i.e. snorkelers and scuba divers) and managers' environmental perceptions at Florida Keys National Marine Sanctuary. The results of the second paper showed that from the recreationists' perspective, managers should overall keep up the good work. From the manager's perspective, seeing a healthy reef and diving on an area free of trash are the two items that they should concentrate on and improve the most. Social science insights can aid decision-making processes and improve recreational experiences for snorkelers and scuba divers while still protecting the marine biodiversity in the Sanctuary.

Keywords: Visitor Use; Marine Protected Areas; Tourism; Florida Keys; Satisfaction; Crowding; Importance Performance Analysis; Recreation Management. 


\section{Table of Contents}

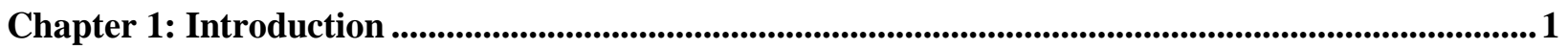

Chapter 2: Paper 1 - User Satisfaction and Crowding at Florida Keys National Marine Sanctuary 4

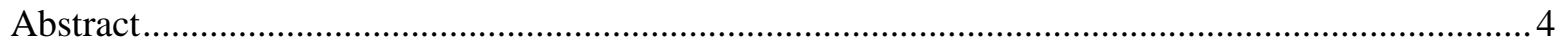

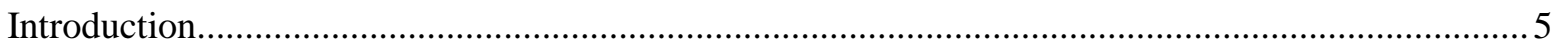

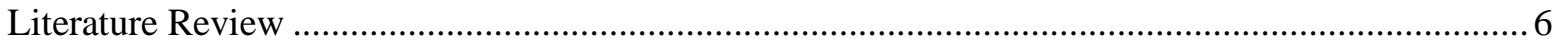

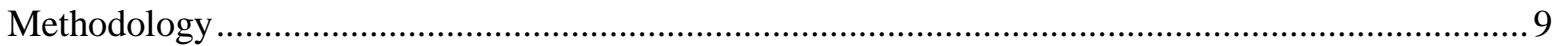

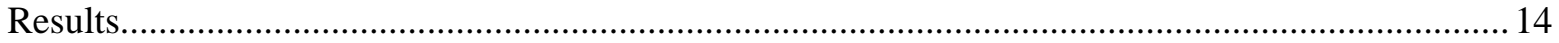

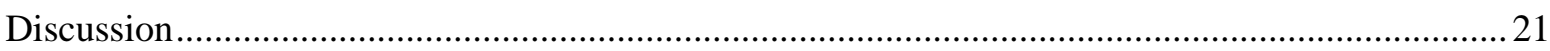

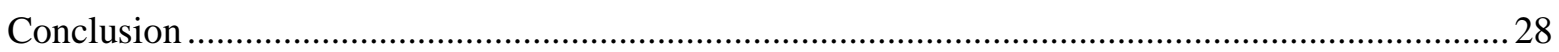

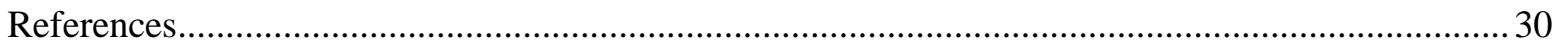

Chapter 3: Paper 2 - An Importance-Performance Analysis of Environmental Perceptions: Florida Keys National Marine Sanctuary Recreationists and Resource Managers .........................................36

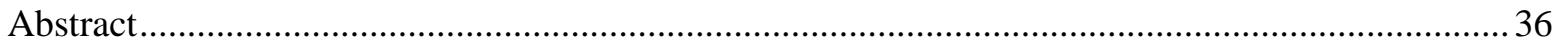

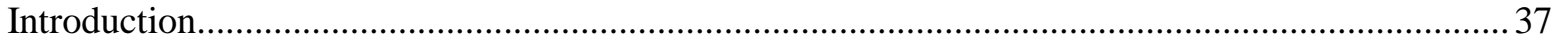

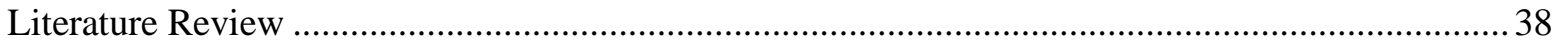

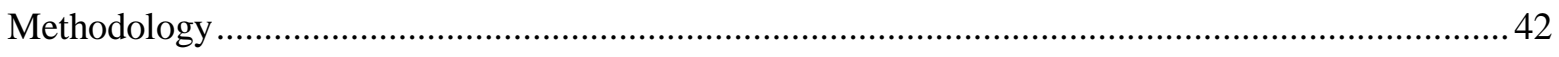

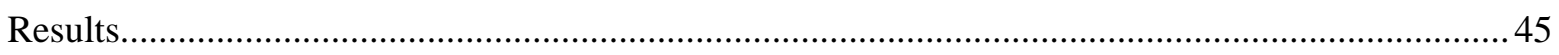

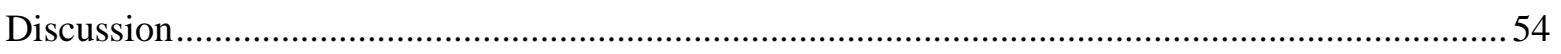

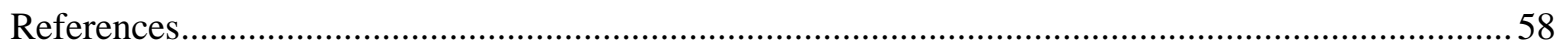

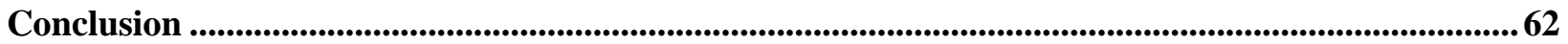

Appendix A: Survey Instrument 1 ................................................................................................................665

Appendix B: Survey Instrument 2.............................................................................................................72 


\section{Chapter 1 Introduction}

The focus of this thesis was to achieve a better understanding of visitor use in Florida Keys National Sanctuary by examining the users' satisfaction, crowding and environmental perceptions. The results of this research are demonstrated as two papers in chapter two and chapter three. Each paper contains its own abstract, introduction, literature review, methodology, results and discussion. The conclusions of this thesis are detailed at the end of this document. This study is part of a bigger project called the National Marine Sanctuaries Visitor Counting Process (NMS-COUNT) (Burns et al., 2020). The NMS-COUNT allows resource managers to gain valid and reliable data among with data collection methodologies to advance predictive capability and understanding of visitors in Marine Protected Areas (MPAs), in this case it is in Florida Keys National Marine Sanctuary.

Before describing the importance of understanding visitor use in MPAs, it is necessary to emphasize that MPAs are not only vital in conserving the marine cultural heritage and supporting vital living systems of the world, but they also ensure that the use of living marine resources is sustained ecologically in those areas (IUCN, 1980; Kelleher, 1999). MPAs allow different types of human activities' use including research, environmental education and tourism. The increasing popularity of MPAs presents a paradox (Hansen, 2015). On one hand, people seek to recreate in unique natural coastal environments with settings that match their needs and desires. On the other hand, the same increased recreational attention may result in negative impacts of the physical and social environment. This is one of the reasons why it is extremely important to manage visitor use in a sustainable way. Managers can face complex challenges while trying to 
provide a successful recreational experience that leaves the visitor extremely satisfied and at the same time, trying to protect the marine natural biodiversity and resources (Winter et al., 2020; Andrew et al., 2020; von Ruschkowski et al., 2013;). Florida Keys National Marine Sanctuary is a touristic destination that offers users multiple recreational activities such as world-class diving, swimming, snorkeling and fishing (NOAA, 2021). Thus there is a need to examine satisfaction, crowding, visitor use patterns, trip characteristics, environmental perceptions and the visitor profile in the Sanctuary.

Chapter two of this thesis examined the satisfaction and crowding of people recreating at Florida Keys National Marine Sanctuary. Online surveys were sent via Qualtrics to email addresses obtained from the state of Florida during the summer of 2020. The targeted sample of this survey were snorkelers and scuba divers. The specific objectives of this paper included: 1) describing the sample of users and their socio-demographics; 2) defining user satisfaction levels for overall trip experience; 3) defining user crowding levels; and 4) identifying if the perception of crowding impacts users' level of satisfaction. By examining and understanding the relationship between satisfaction, crowding and other segmentation characteristics of users, we hope to help define carrying capacity for social thresholds in this setting.

Chapter three of this thesis examined an Importance-Performance Analysis (IPA) of recreationists and managers' environmental perceptions at Florida Keys National Marine Sanctuary. As described in the previous paper, online surveys were sent via Qualtrics to email addresses obtained from the state of Florida during the summer of 2020 and the targeted sample were snorkelers and scuba divers. The specific objectives of this paper included 1) describing the sample of users and their socio-demographics; 2) examining an importance-performance analysis from the recreationists perspective; and 3) examining an importance-performance analysis from 
the manager's perspective. This study provides valuable input from local managers at Florida Keys National Marine Sanctuary and hopes to provide useful insights to aid management strategies.

Throughout chapter two various statistical tests were utilized to predict and analyze results and throughout chapter three simple importance-performance analysis grids were created following Martilla \& James' (1977) technique. Finally, the authors of this study believe that the convergence of social and natural resource research and practices can help managers to create better policies that will maximize human benefits from, and minimize human pressures on ocean and coastal environments. 


\title{
Chapter 2 \\ Paper 1
}

\author{
User Satisfaction and Crowding at Florida Keys National Marine Sanctuary
}

\begin{abstract}
Effective management and monitoring of recreational use are fundamental in marine protected areas. The primary purpose of this study is to examine user's satisfaction levels, crowding levels and the relationship between them at Florida Keys National Marine Sanctuary. Online surveys were sent via Qualtrics to email addresses obtained from the state of Florida during the summer of 2020. The results showed that the respondents felt very satisfied and only slightly crowded while snorkeling or scuba diving during their most recent 2019 trip in the Florida Keys, although satisfaction was still negatively impacted by crowding. An ANOVA showed that satisfaction levels were significantly lower in users who saw more people than they expected. A linear regression indicated significantly lower satisfaction with increasing age. Furthermore, a multiple regression showed that experiencing natural surroundings had a significant positive relationship on overall trip satisfaction, i.e. users that are more satisfied experiencing natural surroundings were also likely to be more satisfied with their overall trip satisfaction. This study suggests that the convergence of social and natural resource research and practices can help managers to create better policies that will maximize human benefits from, and minimize human pressures on, ocean and coastal environments.
\end{abstract}

Keywords: Public Use; Satisfaction; Crowding; Marine Protected areas; Tourism. 


\section{Introduction}

Outdoor recreation in marine protected areas has been increasing over the years (UNWTO, 2020; UNWTO, 2021). People are often attracted to these areas because of the natural qualities of the environment and the recreational opportunities that can be found (Hall \& Page, 2014). The increasing popularity of marine areas presents a paradox (Hansen, 2015). On one hand, people seek to recreate in unique natural coastal environments with settings that match their needs and desires. On the other hand, the same increased recreational attention may result in negative impacts on the physical and social environment. Carrying capacity is a term that emerged within the environmental and outdoor recreation fields of study and can be used as a potential management indicator, leading to management action if necessary (Wagar, 1964; Manning, 2011). A background examination of social carrying capacity leads to two important terms; satisfaction and crowding (Burns et al., 2005; Burns et al., 2003).

The primary purpose of this study is to examine the satisfaction and crowding of people recreating at Florida Keys National Marine Sanctuary. There are different variables that can influence overall satisfaction and crowding levels, and this study compares these variables across recreation user types, such as snorkelers and divers, and other demographic variables in the sanctuary. Specific objectives of this paper include: 1) describing the sample of users and their socio-demographics; 2) defining user satisfaction levels for overall trip experience; 3) defining user crowding levels; and 4) identifying if the perception of crowding impacts users' level of satisfaction. Satisfaction can be identified as a human benefit derived from marine and coastal environments in this study. However, with high levels of recreational use comes the potential for added pressures on these environments. By examining and understanding the relationship 
between satisfaction, crowding, and other segmentation characteristics of users, we hope to help define carrying capacity for social thresholds in this setting.

This study is part of a larger scale project called the National Marine Sanctuaries Visitor Counting Process (NMS-COUNT) (Burns et al., 2020) which will be used to aid NOAA management decisions regarding recreational use in national marine sanctuaries. It is clear that Florida Keys National Marine Sanctuary is a touristic destination that offers users many recreational activities such as world-class diving, swimming, snorkeling, and fishing. The Sanctuary has the world's third largest living coral barrier reef, more than 72,000 people annually visit its Eco-Discovery Center, and ocean-related activities bring the local economy more than $\$ 4.4$ billion in annual revenue and over 70,000 jobs (NMS Foundation, 2021). Therefore, an understanding of social and natural resource carrying capacity can help managers to create better policies that will maximize human benefits from, and minimize human pressures on, ocean and coastal environments.

\section{Literature Review}

The International Union for Conservation of Nature (IUCN) guidelines for Marine Protected Areas (MPAs) state that MPAs are not only vital in conserving the marine cultural heritage and supporting vital living systems of the world, but they also ensure that the use of living marine resources is sustained ecologically in those areas (IUCN, 1980; Kelleher, 1999). Worldwide, approximately 500 million people depend on coral reefs for food, coastal protection, building materials, and income from tourism (Brander \& van Beukering, 2013; Wilkinson, 2008). Coral reefs provide an exceptional number of valuable ecosystem services, they are a key 
source of food, livelihoods and economic opportunity for people. They protect shorelines from erosion, they host a quarter of all known marine species and attract national and international tourists. Tourism, coastal development, and commercial fisheries are three specific sectors that benefit directly from the presence of functional coral reefs (Loomis et al., 2008; NOAA Office for Coastal Management, 2021; UNEP, 2018).

Outdoor recreation in marine protected areas has been increasing over the years (UNWTO, 2020; UNWTO, 2021). People are often attracted to these areas because of the natural qualities of the environment and the recreational opportunities that can be found (Hall, C.M.; Page, 2014). The increasing popularity of marine areas presents a paradox (Hansen, 2015). On one hand, people seek to recreate in unique natural coastal environments with settings that match their needs and desires. On the other hand, the same increased recreational attention may result in negative impacts on the physical and social environment. There is a great variety of natural and anthropogenic stressors affecting reefs, including activities such as diving and snorkeling. Divers can collide with reefs and produce short and longer-term damage to corals, resulting in losses that can be exacerbated by the intensity of site use by divers (Uyarra et al., 2009). Understanding the positive and negative impacts caused by people is one of the main reasons why an effective management and monitoring of recreational use is fundamental in marine protected areas.

Carrying capacity is a term that emerged within the environmental and outdoor recreation fields of study and can be used as a potential management indicator, leading to management action if necessary. Wagar was one of the first authors to relate the term to recreational use, and stated that wild lands should have maximum recreational carrying capacity limits (Wagar, 1964). Wagar analyzed the human, ecological and management considerations that must go into 
administrative decisions to limit recreational use. Carrying capacity can be defined as the amount of users that can be accommodated at a given site or area without negatively affecting the biological environment or the experience, and this definition is still applicable across contemporary settings (Manning, 2011; B. Shelby \& Heberlein, 1987). There are three types of carrying capacity: resource, social and managerial (Manning, 2011). Determining the carrying capacity of an area is important from an ecological and social perspective (von Ruschkowski et al., 2013). Thus, it is critical to accommodate the optimum levels of use in order to guarantee the best possible recreational experience for visitors while preserving natural resources (Burns et al., 2020). Studies have shown that the concept of social carrying capacity is more common in the U.S than in European countries (von Ruschkowski et al., 2013). The accelerating growth of recreational use on western U.S stimulated the adoption of this concept (McCool \& Lime, 2001). Therefore, it is suggested that managers incorporate social carrying capacity issues into recreation ecology studies (Liddle, 1997) in order to improve the integration of scientific disciplines (von Ruschkowski et al., 2013).

A background examination of social carrying capacity leads to two important terms; satisfaction and crowding. There are many different variables that can influence overall satisfaction and crowding levels (Burns \& Graefe, 2005). To understand the concept of satisfaction, it is necessary to understand the basis of expectancy disconfirmation.

Disconfirmation takes place "when there are differences between what one receives and what he or she wanted to receive in an experience" (Burns et al., 2003). The expectancy theory suggests that recreationists fulfill selected needs and motivations while recreating, therefore, the congruence between expectations and outcomes is typically defined as satisfaction (Manning, 
2011). In this case, it is also known that finding specific fauna and impressive ecosystems can be key expressive attributes of satisfaction in protected areas (Carvache-Franco et al., 2020).

On the other hand, crowding is related to an individual judgment on the density of people. Crowding is defined as a negative evaluation of density and involves a value judgment that the density or number of encounters with other visitors is too many (Vaske \& Shelby, 2008). The normative approach suggests that use level is not interpreted negatively as crowding until it is perceived to disrupt the users' objectives or values. It is important to recognize that the recreation experience can have potential threats to satisfaction resulting from crowding or conflicts between recreationists (Burns et al., 2003; Manning, 2011; B. Shelby \& Heberlein, 1987). The perception of crowding can also be influenced by the amount of people that a user expects to see, hence it is suggested that management agencies provide visitors with information on the amount of people that can be expected in certain areas (Graefe \& Fedler, 1986; Vaske \& Shelby, 2008).

\section{Methodology}

Study Area

Florida Keys National Marine Sanctuary is part of the National Marine Sanctuary System and is administered by the National Oceanic and Atmospheric Administration (NOAA) Office of National Marine Sanctuaries (ONMS). NOAA defines National Marine Sanctuaries as "protected waters that include habitats such as rocky reefs, kelp forests, deep-sea canyons, and underwater archaeological sites" (NOAA, 2021). The National Marine Sanctuaries Act established Florida Keys National Marine Sanctuary for the purpose of "managing and protecting the conservation, recreational, ecological, historical, scientific, educational, cultural, archaeological or aesthetic 
resources and qualities of a national marine sanctuary" (NMSA, 1992). Florida Keys National Marine Sanctuary was designated on November 16, 1990 and now protects 2,900 square nautical miles of waters. The boundaries of the sanctuary are from south of Miami, Florida to the Dry Tortugas, although it excludes Dry Tortugas National Park (Figure 1). This sanctuary protects a coral barrier reef, extensive seagrass beds, mangrove-fringed islands, more than 6,000 species of marine life, as well as historical and archeological heritage such as shipwrecks (NOAA Florida Keys, 2021).

Figure 1. Florida Keys National Marine Sanctuary

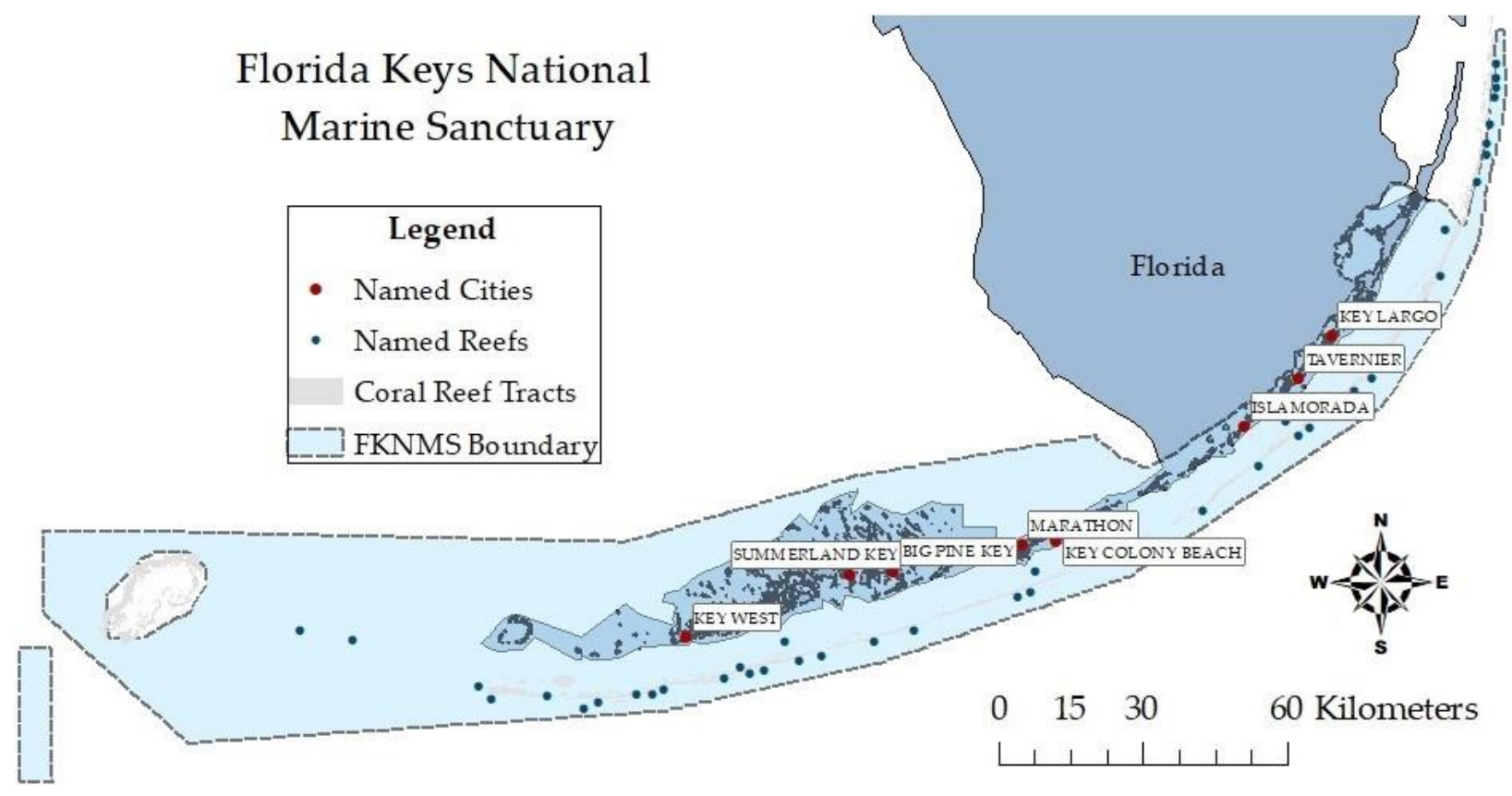

\section{$\underline{\text { Data Collection }}$}

Two survey instruments, one designed for general use information and one designed for more economic information related to SCUBA divers and snorkelers in Florida Keys National Marine Sanctuary were part of the NMS-COUNT project (Burns et al., 2020) and were the two survey instruments used for this study (Appendix A and B). The questions used in this study from the survey instruments were designed to measure recreational satisfaction and crowding 
levels. The survey instruments used for the NMS-COUNT project included other questions related to the users' trip characteristics. The authors will examine the relationships between coral reef perceptions and satisfaction in a different manuscript.

The examination of overall satisfaction measurement varies throughout the outdoor recreation literature. Many studies have paid attention to overall satisfaction, measured with a single item (Burns et al., 2003; Cronin \& Taylor, 1992; Howat et al., 1999). In this study, the overall trip satisfaction scores were collected using a single item, 10-point scale with increasing values meaning higher satisfaction level (i.e. 1 being not at all satisfied and 10 being extremely satisfied). However, other studies have used multiple-item scales developed to measure alternative dimensions of satisfaction and some studies stated that multiple-item scales are more useful than single-item measures (Graefe \& Fedler, 1986; Lee et al., 2007; Manning, 2011; Parasuraman et al., 1988). Therefore, a second question about satisfaction was included in the survey, this question asked respondents to rate the satisfaction of eight different environmental items on a scale from 1 to 5 with 1 being not at all satisfied and 5 being extremely satisfied.

Crowding scores were similarly collected using a 9-point scale with four levels of description, i.e. not at all crowded, slightly crowded, moderately crowded and extremely crowded (Heberlein \& Vaske, 1977). This single-item crowding measure has been widely used in outdoor recreation research (Vaske \& Shelby, 2008). On the other hand, studies often evaluate the density of other participants as negative or neutral, but do not always have the option of assess the density of participants positively (Gigliotti \& Chase, 2014). In order to give the respondents a second alternative to evaluate crowding, they were asked to report how the number of people they saw compared with what they expected to see, the six answer options varied from a lot less than expected to a lot more than expected. Finally, basic socio-demographics, such as 
age, gender, ethnicity, race, education, income and residence, were also collected and examined.

The questions selected from the survey instrument can be seen in Table 1.

Table 1. Questions selected from survey instrument for use in analysis in this study, shown with response scale and mean values or response percentages

\begin{tabular}{lll}
\hline \hline Questions & Answers & Mean/Valid \\
& & Percent $(\%)$ \\
\hline
\end{tabular}

1. Consider your most recent 2019 snorkeling or $\quad$ Scale from 1 to 10

scuba diving trip to the Florida Keys National Marine $1=$ Not at all Satisfied

Sanctuary. Overall, how satisfied were you with your $10=$ Extremely Satisfied

experience? ${ }^{1}$

2. How satisfied were you with each of the following Seeing a healthy reef 3.2

during your most recent trip to the Florida Keys $\quad$ Diving in an uncrowded area 3.3

National Marine Sanctuary? ${ }^{2}$

Experiencing good underwater clarity $\quad 3.5$

Experiencing natural surroundings $\quad 3.8$

$1=$ Not at all Satisfied

Experiencing adventure $\quad 3.7$

$5=$ Extremely Satisfied $\quad$ Experiencing a clean reef 3.4

Availability of an open mooring buoy $\quad 3.2$

Diving on an area free of discarded $\quad 3.4$

fishing traps, line, or tackle

3. How crowded did you feel while actively Scale from 1 to 9

snorkeling or diving during your most recent $2019 \quad 1=$ Not Crowded at all

trip in the Florida Keys National Marine Sanctuary? ${ }^{3} 9=$ Extremely Crowded

4. On your most recent 2019 snorkeling or scuba A lot less than you expected $\quad 7.6 \%$ diving trip to a coral reef in the Florida Keys National A little less than you expected $\quad 9.7 \%$

Marine Sanctuary, how did the number of people you About what you expected $56.5 \%$

saw compare with what you expected to see? ${ }^{4} \quad$ A little more than you expected $\quad 9.2 \%$

A lot more than you expected $\quad 10.4 \%$

You didn't have any expectations $\quad 6.6 \%$

1 (Burns et al., 2003; Cronin \& Taylor, 1992; Howat et al., 1999); ${ }^{2}$ (Graefe \& Fedler, 1986; Lee et al., 2007; Manning, 2011; Parasuraman et al., 1988); ${ }^{3}$ (Heberlein \& Vaske, 1977; Vaske \& Shelby, 2008);

${ }^{4}$ (Gigliotti \& Chase, 2014).

While the original aim for this study was to collect data through in-person interviews in

Florida Keys National Marine Sanctuary, the ongoing COVID-19 pandemic precluded in-person activities. Accordingly, a database of active recreationists who hold various Florida outdoor recreation licenses (e.g., fishing licenses, boating licenses, diving licenses) was used to obtain a sample for the study. The database included people from around the United States, with the greatest proportion $(89 \%)$ of the responses from Florida. A small minority of respondents came 
from states other than Florida (e.g., 4\% from Michigan, 2\% from Alabama, 1\% from Ohio, 1\% from Illinois). The survey distribution followed the Dillman method (Dillman, D. A., \& Bowker, 2001), which describes the most desirable web surveying practices for contacting and reminding respondents about survey participation. After the first personalized email with the survey link, two weekly reminder emails were sent to the non-respondents to increase the likelihood of response. The respondents were able to skip questions while taking the survey on Qualtrics. For this reason, valid and missing numbers vary greatly for each variable, resulting in variance of sample size for specific questions (Tables $2,3, \& 6$ ). The total number of effective survey contacts was 1,077. Effective survey contacts are represented as those recipients who received the email to a legitimate email address and opened the email (was not sent to junk mail folder, etc.). From those effective survey contacts, 791 surveys were completed, for an effective response rate of $73.4 \%$.

\section{Data Analysis}

The database with the survey responses was exported from Qualtrics as a CSV file, then imported and analyzed on the IBM Statistical Package for the Social Sciences (SPSS) v.27. The majority of the answers were recoded from categorical to numerical in order to run statistical tests (e.g. $1=$ male, $2=$ female). An alpha level of 0.05 was used to determine significance for all analyses. This study is divided in four sections: 1) sample profile; 2) satisfaction; 3) crowding; and 4) relationship between satisfaction and crowding. The first section describes the sociodemographic profile of survey respondents with the valid percentage and frequencies of each item. The second section is about satisfaction and describes the means, valid percent and frequencies of satisfaction levels by socio-demographics and user type (i.e. snorkeler vs. scuba diver). It also contains an independent t-test to see the difference in the overall satisfaction level 
mean between user types, independent sample t-tests and ANOVAs to identify the mean satisfaction level differences between each socio-demographic group, a regression to test the relationship of age and overall satisfaction, and a regression to test the relationship between overall satisfaction and satisfaction of a list of environmental items.

The third section is about crowding, and similarly to satisfaction, this section describes means, valid percentages, and frequencies of crowding levels by socio-demographics and user types. Independent t-tests and ANOVAs of crowding level between user types and sociodemographic groups, as well as regression of age and crowding level are used and presented for analyses. The fourth and final section is about the relationship and influence that crowding has on overall satisfaction. This section presents a linear regression to test the relationship between crowding and satisfaction levels. It also presents an ANOVA of crowding expectations and overall satisfaction.

\section{Results}

$\underline{\text { Sample Profile }}$

The socio-demographic profile of the respondents included their residence status, age, sex, race, ethnicity, education and income levels (Table 2). The results showed that a majority $(75.2 \%)$ of the respondents were visitors, while $16.2 \%$ were permanent residents of Monroe County, Florida and $8.6 \%$ were seasonal residents of Monroe County. The average age of the respondents was $53.4 \pm 0.6$ years and the majority were male $(75.5 \%)$. Regarding race and ethnicity, $91.5 \%$ classified themselves as white and $82.9 \%$ as non-Hispanic. Overall, the sample was highly educated with a high income. More than half of the respondents $(66.2 \%)$ had at least a college graduate completed and a considerable number (62.8\%) indicated an annual household 
income of over $\$ 100,001$. According to the survey data, only $8.7 \%$ of the respondents have visited the Florida Keys once, while $75 \%$ of the respondents have visited the area more than once. Therefore, the majority of the respondents are considered to be return visitors. The statistical analyses performed showed that satisfaction level did not differ significantly across any of the presented socio-demographic groups.

Table 2. Socio-demographic profile of survey respondents, shown with frequency and percentage of responses for each optional survey question

\begin{tabular}{|c|c|c|c|c|}
\hline Socio-demographic & Profile & $\begin{array}{c}\text { Valid } \\
\text { Percent (\%) }\end{array}$ & Frequency & $N$ \\
\hline \multirow[t]{3}{*}{ Residence } & Permanent resident & 16.2 & 53 & \multirow{3}{*}{327} \\
\hline & Seasonal resident & 8.6 & 28 & \\
\hline & Visitor & 75.2 & 246 & \\
\hline \multirow[t]{2}{*}{ Sex } & Male & 75.5 & 244 & \multirow[b]{2}{*}{323} \\
\hline & Female & 24.5 & 79 & \\
\hline \multirow[t]{3}{*}{ Age Recoded } & 30 or younger & 3.5 & 11 & \multirow{3}{*}{315} \\
\hline & $31-50$ & 29.8 & 94 & \\
\hline & 51 and over & 66.7 & 210 & \\
\hline \multirow[t]{2}{*}{ Ethnicity } & Hispanic & 17.1 & 55 & \multirow[b]{2}{*}{322} \\
\hline & Non-Hispanic & 82.9 & 267 & \\
\hline \multirow[t]{2}{*}{ Race Recoded } & White & 91.5 & 291 & \multirow[b]{2}{*}{318} \\
\hline & Non-White & 8.5 & 27 & \\
\hline \multirow[t]{4}{*}{ Education } & High school graduate & 7.8 & 25 & \multirow{4}{*}{320} \\
\hline & Some college & 25.9 & 83 & \\
\hline & College graduate & 38.1 & 122 & \\
\hline & Post graduate & 28.1 & 90 & \\
\hline \multirow[t]{3}{*}{ Income Recoded } & Under $\$ 50,000$ & 7.8 & 23 & \multirow{3}{*}{296} \\
\hline & $\$ 50,001-\$ 100,000$ & 29.4 & 87 & \\
\hline & Over $\$ 100,001$ & 62.8 & 186 & \\
\hline
\end{tabular}

\section{$\underline{\text { Overall Satisfaction Level }}$}

Considering the most recent 2019 snorkeling or scuba diving trip to Florida Keys

National Marine Sanctuary, the respondents rated their overall satisfaction level as $8.1 \pm 0.1$ on average. The median value reported for this variable was 8.5 and the mode was 10 (Table 3). 
Table 3. Means of overall satisfaction level by socio-demographics across optional survey question responses

\begin{tabular}{|c|c|c|c|c|c|}
\hline \multicolumn{6}{|c|}{ Overall Trip Satisfaction Level } \\
\hline Socio-demographic & Profile & $M$ & $S D$ & $S E$ & $N$ \\
\hline \multirow[t]{3}{*}{ Residence } & Permanent resident & 8.1 & 1.8 & 0.2 & 50 \\
\hline & Seasonal resident & 8.5 & 1.8 & 0.3 & 28 \\
\hline & Visitor & 8.0 & 2.1 & 0.1 & 219 \\
\hline \multirow[t]{2}{*}{ Gender } & Male & 8.1 & 2.1 & 0.1 & 215 \\
\hline & Female & 8.3 & 1.9 & 0.2 & 75 \\
\hline \multirow[t]{3}{*}{ Age Recoded } & 30 or younger & 8.5 & 2.5 & 0.7 & 11 \\
\hline & $31-50$ & 8.3 & 1.8 & 0.1 & 91 \\
\hline & 51 and over & 7.9 & 2.1 & 0.1 & 183 \\
\hline \multirow[t]{2}{*}{ Ethnicity } & Hispanic & 8.3 & 2.1 & 0.3 & 51 \\
\hline & Non-Hispanic & 8.0 & 2.0 & 0.1 & 238 \\
\hline \multirow[t]{2}{*}{ Race Recoded } & White & 8.2 & 2.0 & 0.1 & 263 \\
\hline & Non-White & 7.6 & 2.7 & 0.5 & 22 \\
\hline \multirow[t]{4}{*}{ Education } & High school graduate & 8.1 & 2.1 & 0.4 & 21 \\
\hline & Some college & 8.3 & 2.1 & 0.2 & 72 \\
\hline & College graduate & 8.1 & 2.0 & 0.2 & 107 \\
\hline & Post graduate & 7.9 & 2.0 & 0.2 & 87 \\
\hline \multirow[t]{3}{*}{ Income Recoded } & Under $\$ 50,000$ & 7.6 & 2.6 & 0.5 & 19 \\
\hline & $\$ 50,001-\$ 100,000$ & 8.4 & 2.0 & 0.2 & 74 \\
\hline & Over $\$ 100,001$ & 8.1 & 1.9 & 0.1 & 173 \\
\hline
\end{tabular}

Note: $M, S D, S E, N$ represent mean, standard deviation, standard error of mean and total responses, respectively. There were no significant differences found between the mean groups.

Independent sample t-tests and ANOVAs were run to identify the mean satisfaction level differences between each socio-demographic group. No statistical differences were detected across all groups with respect to overall satisfaction level. Linear regression between overall satisfaction and age showed a significant $\left(p=0.008 ; \beta=-0.157 ; \mathrm{R}^{2} \mathrm{adj} .=0.021\right)$ negative relationship. This means that for every additional year in age, the mean satisfaction level is expected to drop by 0.157 units (Figure 2). 
Figure 2. Linear regression results for overall satisfaction level and age.

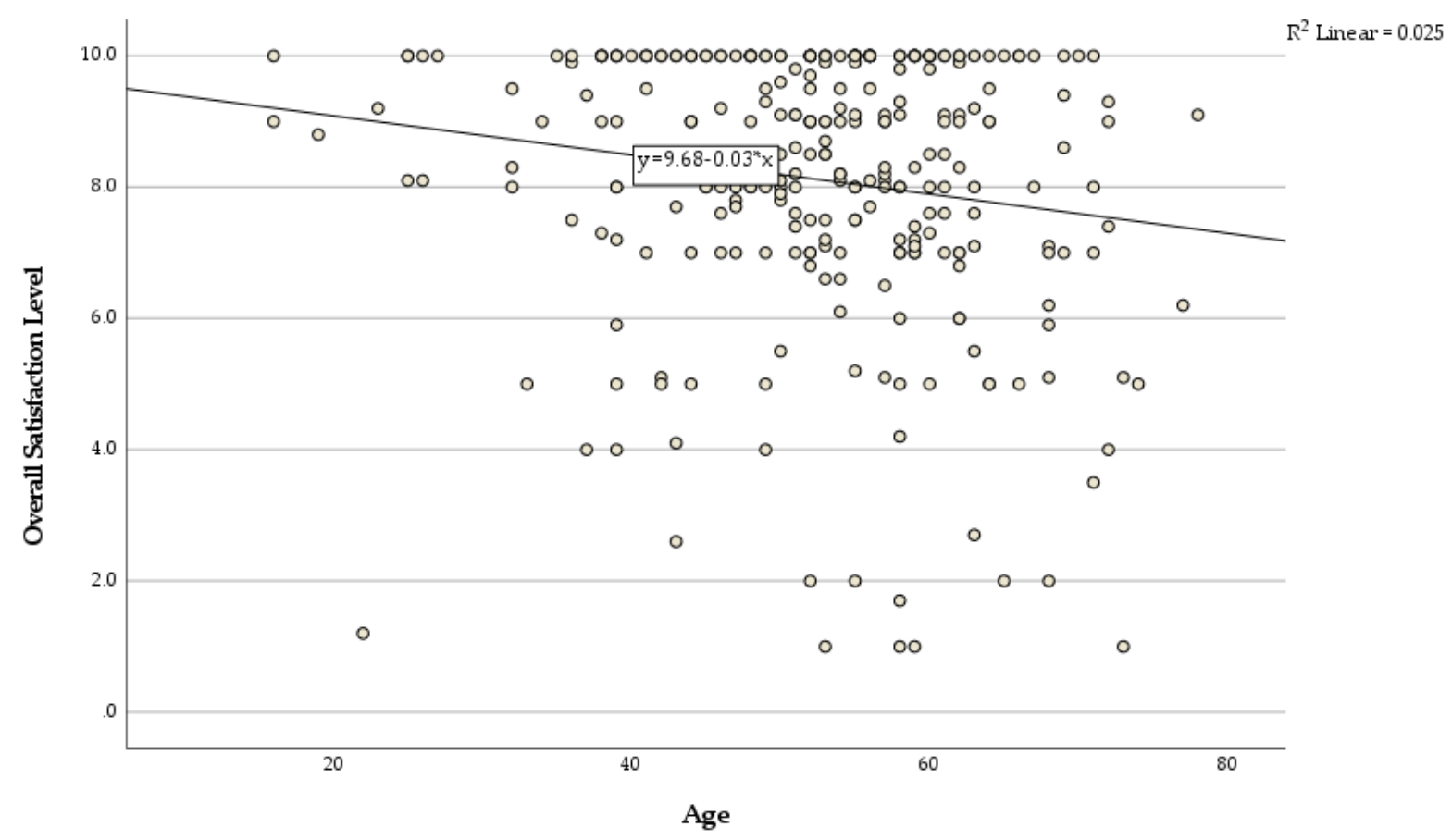

Respondents were asked to rate how satisfied they were with a set of eight environmental items in their most recent trip to Florida Keys National Marine Sanctuary (Table 4). The results compared overall satisfaction to the eight different environmental predictor values using multiple regression analyses. Out of the total, only the item experiencing natural surroundings $(p=0.013$; $\beta=0.318 ; \mathrm{R}^{2}$ adj. $\left.=0.308\right)$ showed a significant positive relationship. This means that for every unit of satisfaction that increases in this environmental item, the mean of overall trip satisfaction level is expected to go up by 0.31 units. All other non-significant environmental predictor items for overall satisfaction presented weak positive relationships with the exception of two items. Those items were diving in an uncrowded area $\left(p=0.841 ; \beta=-0.023 ; \mathrm{R}^{2}\right.$ adj. $\left.=0.308\right)$ and diving on an area that is free of discarded fish traps, fishing line, or tackle $(p=0.122 ; \beta=$ 0.169; $\mathrm{R}^{2}$ adj. $\left.=0.308\right)$, which presented non-significant weak inverse relationships. 
Table 4. Multiple regression results for overall satisfaction level and satisfaction of environmental items

\begin{tabular}{lccccc}
\hline \multicolumn{1}{c}{ Variable } & $B$ & $95 \%$ CI & $\beta$ & $t$ & $p$ \\
\hline (Constant) & 3.26 & {$[1.94,4.58]$} & & 4.88 & 0.000 \\
Seeing a healthy reef & 0.35 & {$[-0.10,0.81]$} & 0.19 & 1.51 & 0.133 \\
Diving in an uncrowded area & -0.04 & {$[-0.47,0.38]$} & -0.02 & -0.20 & 0.841 \\
Experiencing good underwater clarity & 0.29 & {$[-0.15,0.73]$} & 0.14 & 1.30 & 0.194 \\
Experiencing natural surroundings & 0.72 & {$[0.15,1.29]$} & 0.31 & 2.51 & $\mathbf{0 . 0 1 3}$ \\
Experiencing adventure & 0.10 & {$[-0.37,0.57]$} & 0.04 & 0.41 & 0.679 \\
Experiencing a clean reef & 0.08 & {$[-0.43,0.60]$} & 0.04 & 0.33 & 0.738 \\
Availability of an open mooring buoy & 0.15 & {$[-0.14,0.46]$} & 0.09 & 1.03 & 0.302 \\
Diving on an area free of discarded fishing & -0.28 & {$[-0.65,0.07]$} & -0.16 & -1.55 & 0.122 \\
traps, line, or tackle & & & & &
\end{tabular}

Note: $R^{2}$ adj. $=0.308 . C I=$ confidence interval for $B . * p<0.05$.

\section{Crowding Level}

The survey instrument included a question that asked how crowded the respondents felt while actively snorkeling or diving during their most recent 2019 trip at Florida Keys National Marine Sanctuary. The scores varied from 1 being not crowded at all to 9 being extremely crowded. The results showed that the crowding mean level was $4.3 \pm 0.1$, the median reported for this variable was 4.2 and the mode was 5.0. These responses fall into the category of slightly and moderately crowded (Figure 3). The number of valid answers for this question was 371.

Figure 3. Overall crowding level scale, shown with mean and mode values from survey responses

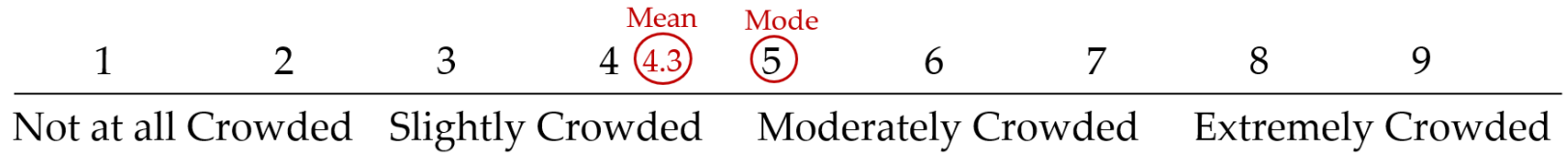

An independent sample t-test was run to identify the differences in the crowding level mean between user types, (i.e. snorkelers and scuba divers). However, no statistical differences were detected between these groups $(p=0.938)$. Consequently, the data showed that snorkelers 
$(4.3 \pm 0.1)$ and scuba divers $(4.3 \pm 0.2)$ had the same average crowding level. Independent sample t-tests and ANOVAs were run to identify the mean crowding level differences between each socio-demographic group. The results showed that crowding level did not differ significantly across these groups except for the education variable $(p=0.05)$. Finally, a linear regression was run between crowding and age to predict the relationship between these two variables and the results showed that there are no significant differences $(p=0.442 ; \beta=-0.046$; $\mathrm{R}^{2}$ adj. = -0.001). The means of overall crowding level by socio-demographic categories in survey responses are shown in Table 5.

Table 5. Means of overall crowding level by socio-demographic categories in survey responses

\begin{tabular}{|c|c|c|c|c|c|}
\hline \multicolumn{6}{|c|}{ Overall Crowding Level } \\
\hline Socio-demographic & Profile & $M$ & $S D$ & $S E$ & $N$ \\
\hline \multirow[t]{3}{*}{ Residence } & Permanent resident & 4.6 & 2.2 & 0.3 & 51 \\
\hline & Seasonal resident & 4.1 & 2.1 & 0.4 & 27 \\
\hline & Visitor & 4.2 & 2.1 & 0.1 & 215 \\
\hline \multirow[t]{2}{*}{ Gender } & Male & 4.4 & 2.2 & 0.1 & 214 \\
\hline & Female & 4.2 & 2.1 & 0.2 & 74 \\
\hline \multirow[t]{3}{*}{ Age Recoded } & 30 or younger & 3.9 & 2.1 & 0.6 & 11 \\
\hline & $31-50$ & 4.5 & 2.2 & 0.2 & 86 \\
\hline & 51 and over & 4.3 & 2.1 & 0.1 & 185 \\
\hline \multirow[t]{2}{*}{ Ethnicity } & Hispanic & 4.5 & 2.3 & 0.3 & 50 \\
\hline & Non-Hispanic & 4.3 & 2.1 & 0.1 & 237 \\
\hline \multirow[t]{2}{*}{ Race Recoded } & White & 4.4 & 2.1 & 0.1 & 258 \\
\hline & Non-White & 3.7 & 2.4 & 0.4 & 25 \\
\hline \multirow[t]{4}{*}{ Education* } & High school graduate & 4.7 & 2.2 & 0.4 & 21 \\
\hline & Some college & 3.9 & 2.1 & 0.2 & 72 \\
\hline & College graduate & 4.7 & 2.2 & 0.2 & 106 \\
\hline & Post graduate & 4.1 & 2.1 & 0.2 & 86 \\
\hline \multirow[t]{3}{*}{ Income Recoded } & Under $\$ 50,000$ & 5.4 & 2.5 & 0.5 & 20 \\
\hline & $\$ 50,001-\$ 100,000$ & 4.4 & 2.3 & 0.2 & 74 \\
\hline & Over $\$ 100,001$ & 4.2 & 2.1 & 0.1 & 171 \\
\hline
\end{tabular}

Note: $M, S D, S E, N$ represent mean, standard deviation, standard error of mean and total responses, respectively. $* p=0.05$. 


\section{$\underline{\text { Relationship between Satisfaction and Crowding }}$}

Visitors can have reductions in satisfaction resulting from crowding and for that reason, research indicates that crowding perceived levels can negatively influence the overall trip satisfaction (Burns et al., 2003). However, the linear regression between overall satisfaction and crowding levels was not significant $\left(p=0.062 ; \beta=-0.099 ; \mathrm{R}^{2}\right.$ adj. $\left.=0.007\right)$ in this study. Another question in the survey instrument assessed crowding level through expectation of the number of people seen compared with expectation. An ANOVA among satisfaction level and this alternative measurement of crowding level indicated significant differences across the six different crowding scale points $(\mathrm{F}=7.443 ; p=0.000)$. Multiple comparisons using least significant differences illustrate a generally negative relationship between crowding expectation outcome and satisfaction (Figure 4).

Figure 4. Means plot of ANOVA between satisfaction and crowding expectation/outcome with standard error bars

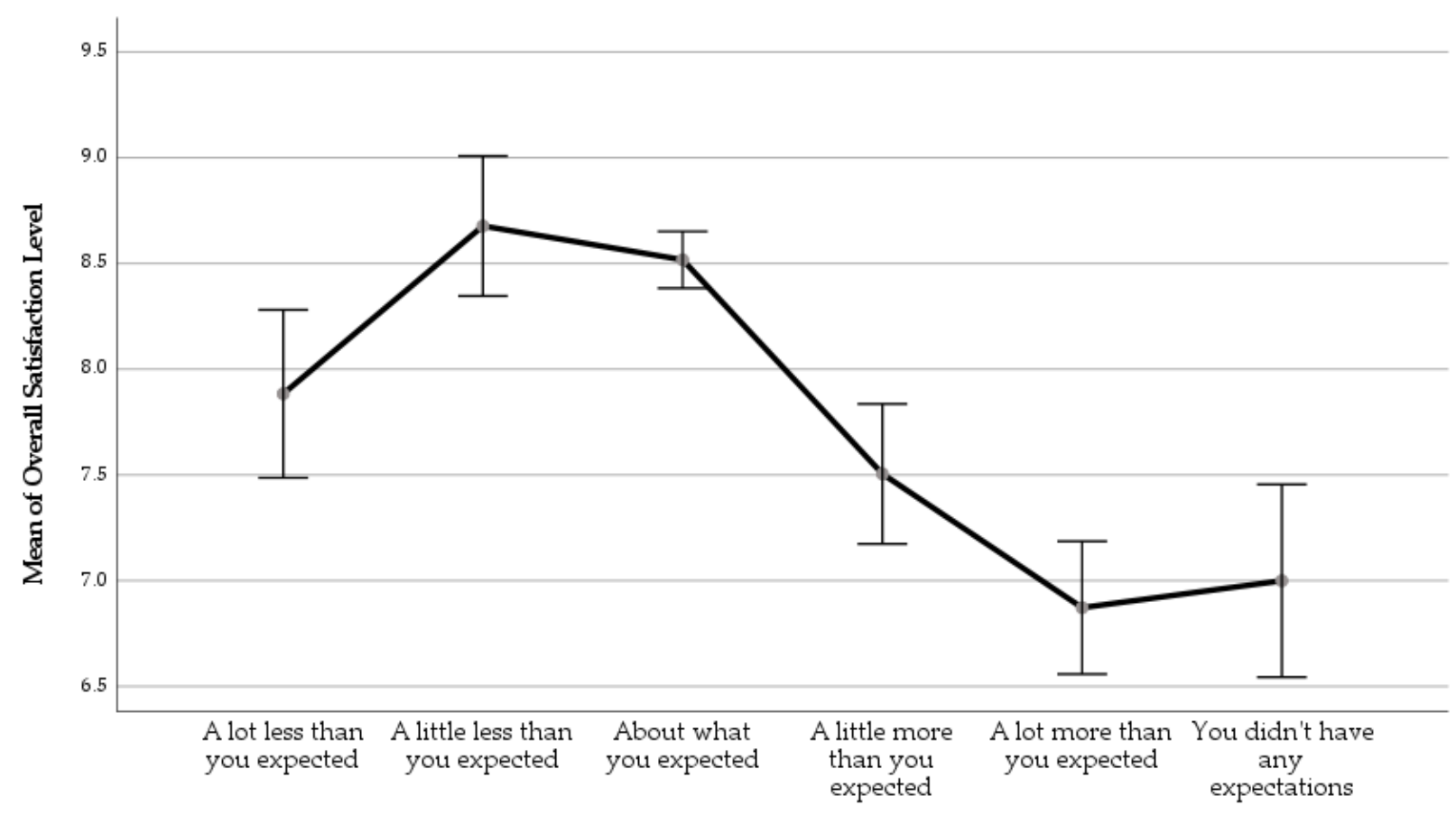

Crowding Expectation and Outcome 


\section{Discussion}

The Diving Equipment \& Marketing Association (DEMA) published the 2021 profile of recreational scuba divers and snorkelers in the U.S. The profile of Open Water-level (i.e. entrylevel divers) showed that the mean age is 29.7 years and $60 \%$ are males. Regarding annual household income, $69.4 \%$ of the divers make between $\$ 100,000$ and $\$ 150,000$. The majority of the divers $(65.8 \%)$ completed college or graduate school and 99\% own their home (DEMA, 2021). Similarly, the sample of users in this study were predominantly middle-aged, welleducated, white males with high income. Understanding the socio-demographic profile of the users in Florida Keys National Marine Sanctuary is fundamental to provide equitable and inclusive recreational opportunities. Unfortunately, despite a relatively high ethnically and racially diverse population in the United States, studies indicate that minorities are underrepresented in outdoor recreation and visitation (Winter et al., 2020). Research has shown gender differences exist in the outdoors, emphasizing the fact that men are more likely to participate in outdoor recreation activities than women (Asselin, 2019; Godtman et al., 2020; Rosa et al., 2020). Simultaneously, the sample of respondents in this study indicated that $24.5 \%$ were female while $\mathbf{7 5 . 5 \%}$ were male. Race and ethnicity are also a key element of diversity and inclusion. Results of this study showed that only $8.5 \%$ of the sample identified as non-White and $17 \%$ identified as Hispanic. Therefore, there is little involvement of non-White populations and a negligible proportion of Hispanic population recreating in Florida Keys National Marine Sanctuary.

The underrepresentation of minority populations (e.g. Hispanic, Black, American Indian, etc.) suggests that inclusion should be a point of attention in outdoor recreation management (Davis, 2019; Grill et al., 2020). Only a small proportion (7.8\%) of the sample reported an 
annual household income of under $\$ 25,000$. This suggests that people with very low income levels were not captured in the surveyed activity types within the sanctuary (Burns \& Graefe, 2006). While the majority of respondents were visitors, some of the responses were from permanent residents of the local area around the sanctuary. Permanent residents had higher rates of response than seasonal residents, which could be related to their level of interest and engagement in the visitor use management of this sanctuary. Providing equitable recreation opportunities can be very complex but it can be greatly beneficial for all the stakeholders involved and especially for the conservation of Florida Keys National Marine Sanctuary (Burns \& Graefe, 2006; Sánchez et al., 2020; Winter et al., 2020).

Other research has indicated lower concern about facilities and services provided during recreational use associated with high levels of income and education in users (Burns \& Robinson, 2017). However, this study found no significant relationships or differences among sociodemographic endpoints defined by groups and satisfaction levels. Overall, satisfaction was quite high, and the only significant trend was associated with age when modeled as a continuous variable to indicate lower satisfaction level with increasing age. Some of the suggestions shared by Florida residents in the Statewide Comprehensive Outdoor Recreation Plan (SCORP) indicated that there should be an improvement in the variety of recreational opportunities for people of all ages (Magnini \& Chuck, 2017). Research has shown that the aging population, especially baby boomers, are known by having good health conditions, high incomes and the desire to recreate outdoors (Robinson et al., 2008; Ziegler, 2002). Respondents that are 51 years or older and have household incomes over $\$ 100,001$ made up the majority of the sample of this study. This could mean that the visitors in the Sanctuary might spend considerable amounts of money during their visit. Visitors often spend money on food in restaurants, lodging, 
transportation and recreational equipment. Therefore, it is likely that affluent visitors bring significant financial contribution to the local economy of Florida Keys National Marine Sanctuary. It is also important to remember that satisfaction can be linked to the fulfillment of motivations and expectations (Graefe \& Burns, 2013). Therefore, studying satisfaction and motivations of this aging population can be a key element to maintain the benefits that come from recreation and go into the social and economic development of this area.

People recreate for different reasons, such as being outdoors, relaxation, getting away from regular routine, being with friends and family, developing skills, etc. In this case, having the opportunity to see a healthy reef, experience adventure, good underwater clarity and natural surroundings while snorkeling or scuba diving can influence satisfaction. In this study, experiencing natural surroundings was a significant predictor item that showed a positive relationship to satisfaction. Studies in ecotourism have shown that finding megafaunas and inspiring ecosystems are key attributes of satisfaction in protected areas; other factors can include tranquility and conservation of natural heritage (Carvache-Franco et al., 2020). This research also showed that positive attitudes toward the natural environment are associated with higher levels of satisfaction in the visitation of natural protected areas (de Oliveira et al., 2020). Different people might have different reactions to the same environment, (Ursi \& Towata, 2018) therefore, as a suggestion for future research directions in this field, we recommend a study that identifies differences of satisfaction levels between people with biocentric values and those with anthropocentric values.

This study investigated the crowding levels of users who were actively snorkeling or scuba diving during their most recent 2019 trip in Florida Keys National Marine Sanctuary. The results showed that the crowding mean level was $4.3 \pm 0.1$ which falls under the category of 
slightly crowded. The data showed that crowding was not statistically related to demographics such as income, age and even user type (i.e. snorkeler vs. diver). The results also showed that crowding level did not differ significantly across these groups except for the education variable. Other studies have shown that visitor age is a significant predictor for crowding (Navarro et al., 2012; Rasoolimanesh et al., 2016; Zehrer \& Raich, 2016) and prior studies also found that females are more uncomfortable with crowding than males (Absher \& Lee, 1981; Zehrer \& Raich, 2016). Other types of factors can influence perceived crowding levels, as another study highlighted that expectations regarding use levels significantly influence perceived crowding (Shelby et al., 1983). Factors such as parking waiting time, waiting time at different recreational sites, reported level of use and acceptable level of use can also significantly influence perceived crowding (Burns et al., 2020). Enjoyment may be negatively impacted by crowding for recreationists', but also users may employ a combination of cognitive and behavioral coping strategies to maintain their enjoyment when perceived crowding is high (Jacobsen et al., 2019; Yoon et al., 2021; Zehrer \& Raich, 2016).

Research related to crowding perceptions has been traditionally focused on terrestrial and not on marine settings but there are considerable differences in terms of social carrying capacity between these two environments (Inglish et al., 1999; Serrano Giné et al., 2018). A snorkeler or scuba diver will see structural features of the underwater landscape such as coral reefs in a large variety of shapes and sizes while the person is floating or swimming above them (Shafer et al., 1998). Research indicates that coral reefs are unfamiliar environments to most people and visitors have different cognitive perceptions when interpreting the features they see around them (Inglish et al., 1999). On top of having a unique underwater experience surrounded by marine biodiversity, having multiple unexpected encounters with different people may affect the 
recreational experience. A recommendation for future research projects in this topic would be to add a different question in the survey instrument that asks about the perception of crowding while snorkeling and scuba diving while being underwater in a specific site (e.g. Molasses Reef). First-time visitors can also have different perceptions from repeat visitors (Burns, 2000). In this case those who are more experienced and specialized in marine recreation hold stronger preferences for the number of people they observe in the setting and may be less tolerant than novice first-time visitors. This suggests that experienced snorkelers and scuba divers may seek feelings of solitude as an important component of their experience (Inglish et al., 1999). The respondents of this study reported to feel somewhat crowded while snorkeling and diving in Florida Keys National Marine Sanctuary. Even though it is not a high level of crowding, (crowding mean $=4.3$ on 9-point scale) this result supports the importance of providing opportunities to experience a feeling of solitude while practicing the activity if desired. The findings of this study showed that crowding at Florida Keys National Marine Sanctuary is not an issue today, but there is still a possibility that it may be a problem in the future. Research that monitors recreation is needed in this area to record reliable data of crowding and satisfaction levels today, thus, it will also be possible to compare this data 20 years from now, if needed. An example of this management practice can be seen in a study that started in 2010 on perceived crowding of climbers on Mt. Baker, WA and Mt. Hood, OR (Chuprinko, 2012) and the concept continues to be analyzed in the area until today (Burns et al., 2021).

Monitoring crowding can be complex for managers in marine protected areas thus, further research in this field can facilitate a better understanding of crowding and provide efficient management recommendations that cut across these different user characteristics and expectations. The complexity of monitoring crowding is connected to the visitor use monitoring 
limitations that management agencies often face. These challenges can include factors such as lack of funding, staff and other resources. In addition to that, National Marine Sanctuaries vary in size, may be located along shorelines or may lack a physical boundary when located offshore. Finding ways to facilitate visitor use monitoring can include data collection methods that are cost-effective. A quick example of this are online questionnaires, which usually require less expenses than in-person interviews. The findings about crowding in this study will help managers better understand their visitors and will allow them to provide better services and facilities. Understanding visitation characteristics in Florida Keys National Marine Sanctuary is one of the first steps to accurately estimating the associated benefits and economic contributions.

When overall satisfaction levels were compared in this study across groups categorized by an alternative variable of crowded defined by expectation, significant differences were illustrated. This result indicated that the overall satisfaction levels were higher when the respondents saw a little less people than they expected. At the same time, satisfaction levels were lower when the respondents saw a lot more people than they expected. The number of encounters that a snorkeler or scuba diver has during the practice of the activity and the acceptable number of these are also important. Another study in Florida Keys National Marine Sanctuary showed that as the number of snorkelers or scuba divers increases, the mean acceptance decreases; consequently, scuba divers can tolerate around 10 other divers or snorkelers, while snorkelers can tolerate more snorkelers (around 17) than divers (Vaske et al., 2013).

There is a dearth of research about crowding and satisfaction specifically while snorkeling and scuba diving in marine protected areas. However, other research in different settings also found that crowding has a negative effect on satisfaction ( Burns et al., 2003; Giusti et al., 2019; Torres-Matovelle \& Molina, 2019; Zehrer \& Raich, 2016). This relationship can be 
affected by skill levels and social behaviors of other users (Pikkemaat et al., 2020). A study suggested that delivering appropriate messages at the right time and place can improve the control of visitor flow and crowding, so visitors may be more aware of the number of encounters and avoid crowding if they are more sensitive to large groups of people (Jin et al., 2016). At the same time, educating visitors through different types of interpretation methods can clarify their expectations, minimize their negative feeling of unfavorable situations and maximize their satisfaction (Jin et al., 2016; Inglish et al., 1999). Specific future research directions include a) finding ways to quantitively determine crowding level limits with visitor numbers; and b) addressing the need of enhancing the social diversity of the users in the Sanctuary.

The growth limits and carrying capacity in marine environments must be considered when the objective is a sustainable management of a coastal area (Kim \& Yoon, 2020; Navarro et al., 2012). Activities such as snorkeling and scuba diving are not only related to social perceptions and interactions, but these are also directly related to the impacts on marine biodiversity. It is important to acknowledge the critical connection that human dimensions have in marine natural resources. On one hand, studying social crowding while snorkeling or diving can be a significant indicator of the pressures that are created in the biodiverse ecosystems that are living underwater. On the other hand, satisfaction of snorkelers and scuba divers can be a critical indicator for the economic contribution that outdoor recreation is making in the local socioeconomic development of the area. Therefore, it is crucial to find a balance between the benefits and pressures that human activity can cause in Florida Keys National Marine Sanctuary. 


\section{Conclusion}

The objectives of this study were to describe the sample of users, define user satisfaction

levels, define user crowding levels, and identifying the relationship between these two endpoints. The results and discussion of this study showed that there is a need for enhancing the sociodemographic diversity of users that visit this sanctuary. Creating a destination that is accessible for all different types of populations, especially one that includes minorities, can be a complex challenge. However, other studies showed that involving all types of populations in recreational activities has benefits beyond society, as diverse users may even promote the conservation of the sanctuary in a myriad of pathways (Burns \& Graefe, 2006; Sanchez et al., 2020; Winter et al., 2020). This thought comes from the idea that we as humans protect what we know and care about, consequently, it is harder to protect what we do not know.

Crowding is a negative individual judgment that can be a good indicator for carrying capacity management. Although the findings of this study indicated that snorkelers and scuba divers of the Florida Keys National Marine Sanctuary felt intermediate crowding levels, this needs to be a point of attention for managers in order to avoid increases in such levels. Managers can take different actions to prevent crowding. Examples of these actions include: a) permits that can be reserved online by the visitors to coordinate times of use; b) studies that establish a biological carrying capacity number for each coral reef site to limit the number of visitors; c) educate the visitor with time in advance to provide accurate information on how the recreational experience often looks like; among others.

The snorkelers and divers of this study felt very satisfied overall during their trip experience and this is a good indicator that helps monitoring if these users are fulfilling their needs and desires. It is likely that managers in marine protected areas focus high levels of their 
research attention in natural sciences (Bennett, 2017), however, this study emphasizes the importance of social sciences to better manage national marine sanctuaries in a way that is sustainable and ecologically balanced. 


\section{References}

Absher, J. D., \& Lee, R. G. (1981). Density as an incomplete cause of crowding in backcountry settings. Leisure Sciences, 4(3), 231-247. https://doi.org/10.1080/01490408109512965

Asselin, J. (2019). Outdoor women: Thinking about gender, self, and environment through outdoor enskillment programs. Anthropologica, 61(2), 283-295. https://doi.org/10.3138/anth.2017-0016

Bennett, N. J., Roth, R., Klain, S. C., Chan, K., Christie, P., Clark, D. A., ... \& Wyborn, C. (2017). Conservation social science: Understanding and integrating human dimensions to improve conservation. biological conservation, 205, 93-108.

Brander, L., \& van Beukering, P. (2013). The Total Economic Value of U.S. Coral Reefs: a Review of The Literature. NOAA Coral Reef Conservation Program, 32.

Burns, R. C. (2000). An Examination of Service Quality Indicators as a Predictor of Customer Satisfaction at US Water-based Recreation Areas. Doctoral dissertation, Pennsylvania State University.

Burns, R., Leveque, J., Allen, M., Arnberger, A., \& Kainzinger, S. (2020). Investigating Crowding at the Lower Youghiogheny River, Pennsylvania, U.S. Journal of Park and Recreation Administration, August. https://doi.org/10.18666/jpra-2020-10127

Burns, Robert C.., \& Graefe, A. R. (2005). Customer satisfaction at water-based outdoor recreation settings: understanding differences across market segments. The Cyber Journal of Applied Leisure and Recreation Research. http://larnet.org/abstracts.html

Burns, Robert C., Allen, M. E., \& Chuprinko, T. L. (2021). Crowding Perceptions at Wilderness Areas on Mount Baker, Washington and Mount Hood, Oregon. International Journal of Wilderness, 27(2).

Burns, Robert C., Andrew, R. G., Allen, M. E., Schwarzmann, D., \& Cardozo Moreira, J. (2020). Conceptualizing the National marine sanctuary visitor counting process for marine protected areas. Journal of Ecotourism, 19(4), 362-372. https://doi.org/10.1080/14724049.2020.1746794

Burns, Robert C., Graefe, A. R., \& Absher, J. D. (2003). Alternate measurement approaches to recreational customer satisfaction: Satisfaction-only versus gap scores. Leisure Sciences, 25(4), 363-380. https://doi.org/10.1080/714044496

Burns, Robert C., \& Robinson, K. F. (2017). Oregon's Aging Population: Relationships Between Facilities, Services, Participation, and Sociodemographics in Outdoor Recreation Settings. Journal of Park and Recreation Administration, 35(4), 13-23. https://doi.org/10.18666/jpra-2017-v35-i4-7569

Burns, Robert C. \& Graefe, A. R. (2006). Toward Understanding Recreation Fees: Impacts on People with Extremely Low Income Levels. Journal of Park and Recreation Administration, 24(1), 1-20.

Carvache-Franco, M., Carvache-Franco, O., \& Carvache-Franco, W. (2020). Exploring The Satisfaction Of Ecotourism In Protected Natural Areas. GeoJournal of Tourism and Geosites, 29(2), 672-683. https://doi.org/10.30892/gtg.29223-498

Chuprinko, T. L. (2012). Mountaineering Motivations and Perceived Crowding : An Examination of Climbers on Mt . Baker, Washington and Mt. Hood, Oregon. West Virginia University. 
Cronin, J. J., \& Taylor, S. A. (1992). Measuring Service Quality: A Reexamination and Extension. Journal of Marketing, 56(3), 55. https://doi.org/10.2307/1252296

DEMA. (2021). 2021 DIVING FAST FACTS: Fast Facts on Recreational Scuba Diving and Snorkeling. Retrieved from https://www.dema.org/store/download.aspx?id=7811B097-8882-4707-A160F999B49614B6

Davis, J. (2019). Black faces, black spaces: Rethinking African American underrepresentation in wildland spaces and outdoor recreation. Environment and Planning E: Nature and Space, 2(1), 89-109. https://doi.org/10.1177/2514848618817480

de Oliveira, A. C. R., Santos, G. E. de O., \& Santos Lobo, H. A. (2020). Environmental Attitudes and Tourist Satisfaction in Overloaded Natural Protected Areas. Journal of Travel Research, 004728752095741. https://doi.org/10.1177/0047287520957419

Dillman, D. A., \& Bowker, D. K. (2001). The web questionnaire challenge to survey methodologists (pp. 5371). Online social sciences.

Gigliotti, L. M., \& Chase, L. (2014). A Bivalent Scale for Measuring Crowding Among Deer Hunters. Human Dimensions of Wildlife, 19(1), 96-103. https://doi.org/10.1080/10871209.2013.811619

Giusti, M. M., Travassos, L. E. P., \& Lobo, H. A. S. (2019). Percepção de lotação e grau de satisfação dos visitantes da Gruta da Lapinha (Parque Estadual do Sumidouro, MG,Brasil). Caderno de Geografia, 29(59), 1139-1160. https://doi.org/10.5752/p.2318-2962.2019v29n59p1139

Godtman, K., Margaryan, L., \& Fuchs, M. (2020). (In) equality in the outdoors: gender perspective on recreation and tourism media in the Swedish mountains. Current Issues in Tourism, 23(2), 233247. https://doi.org/10.1080/13683500.2018.1495698

Graefe, A. R., \& Burns, R. C. (2013). Testing a mediation model of customer service and satisfaction in outdoor recreation. Journal of Outdoor Recreation and Tourism, 3-4(December), 36-46. https://doi.org/10.1016/j.jort.2013.09.006

Graefe, A. R., \& Fedler, A. J. (1986). Situational and subjective determinants of satisfaction in marine recreational fishing. Leisure Sciences, 8(3), 275-295. https://doi.org/10.1080/01490408609513076

Grill, L., Morse, W. C., Schelhas, J., Barlow, B., \& Wyman, M. (2020). Implications of Setting Preference Differences by Race and Gender on the Applicability of a Benefits-Based Management Approach to Recreational Planning. The Journal of Park and Recreation Administration, 38(2), 62-79. https://doi.org/10.18666/pra-2019-9723

Hall, C. \& Page, S. (2014). The Geography of Tourism and Recreation: Environment, Place and Space. In Routledge. https://doi.org/10.1016/0160-7383(79)90100-2

Hansen, A. S. (2015). Monitoring and Managing Outdoor Recreation in Coastal And Marine Areas-What Do We Know And What Do We Need To Know? 2. https://www.researchgate.net/publication/277017170

Heberlein, T. A., \& Vaske, J. J. (1977). Crowding and visitor conflict on the Bois Brule River. 
Howat, G., Murray, D., \& Crilley, G. (1999). The relationships between service problems and perceptions of service quality, satisfaction, and behavioral intentions of Australian public sports and leisure center customers. Journal of Park \& Recreation Administration, 17(2), 42-64.

Inglish, G., Johnson, V., \& Ponte, F. (1999). Crowding Norms in Marine Settings : A Case Study of Snorkeling on the Great Barrier Reef. Environmental Management, 24(3), 369-381.

IUCN. (1980). World Conservation Strategy: Living Resource Conservation for Sustainable Development. In IUCN, Gland, Switzerland.

Jacobsen, J. K. S., Iversen, N. M., \& Hem, L. E. (2019). Hotspot crowding and over-tourism: Antecedents of destination attractiveness. Annals of Tourism Research, 76(June 2018), 53-66.

https://doi.org/10.1016/j.annals.2019.02.011

Jin, Q., Hu, H., \& Kavan, P. (2016). Factors influencing perceived crowding of tourists and sustainable tourism destination management. Sustainability (Switzerland), 8(10), 1-17.

https://doi.org/10.3390/su8100976

Kelleher, G. (1999). Guidelines for Marine Protected Areas. In IUCN, Gland, Switzerland and Cambridge, UK. https://doi.org/10.1071/pc010352

Kim, H. R., \& Yoon, S. Y. (2020). How to help crowded destinations: Tourist anger vs. sympathy and role of destination social responsibility. Sustainability (Switzerland), 12(6). https://doi.org/10.3390/su12062358

Lee, J., Graefe, A. R., \& Burns, R. C. (2007). Examining the Antecedents of Destination Loyalty in a Forest Setting. Leisure Sciences, 29(5), 463-481. https://doi.org/10.1080/01490400701544634

Liddle, M. (1997). Recreation ecology: the ecological impact of outdoor recreation and ecotourism. Chapman \& Hall Ltd.

Loomis, D. K., Anderson, L. E., Hawkins, C., \& Paterson, S. K. (2008). Understanding Coral Reef Use : Snorkeling in the Florida Keys by Residents and Non Residents during 2006-2007. In The Florida Reef Resilience Program. http://frrp.org/FRRP documents/frrp_snorkeling.pdf

Magnini, V., \& Chuck, W. (2017). Florida Statewide Comprehensive Outdoor Recreation Plan: Participation Study 2016-2017. https://floridadep.gov/parks/florida-scorp-outdoor-recreation-florida

Manning, R. E. (2011). Studies in outdoor recreation: Search and research for satisfaction (3rd ed.). Oregon State University.

McCool, S. F., \& Lime, D. W. (2001). Tourism carrying capacity: tempting fantasy or useful reality?. Journal of sustainable tourism, 9(5), 372-388.

Navarro Jurado, E., Tejada, M., Almeida García, F., Cabello González, J., Cortés Macías, R., Delgado Peña, J., Fernández Gutiérrez, F., Gutiérrez Fernández, G., Luque Gallego, M., Málvarez García, G., Marcenaro Gutiérrez, O., Navas Concha, F., Ruiz de la Rúa, F., Ruiz Sinoga, J., \& Solís Becerra, F. (2012). Carrying capacity assessment for tourist destinations. Methodology for the creation of synthetic indicators applied in a coastal area. Tourism Management, 33(6), 1337-1346.

https://doi.org/10.1016/j.tourman.2011.12.017 
NMSA. (1992). National Marine Sanctuaries Act Agencies: 16 U.S.C. $\$ 1431$ et seq.

NMS Foundation. (2021). About Florida Keys. https://marinesanctuary.org/sanctuary/florida-keys/

NOAA. (2021). What is a national marine sanctuary? National Ocean Service Website. https://oceanservice.noaa.gov/facts/nms.html

NOAA Florida Keys. (2021). About Florida Keys National Marine Sanctuary. https://floridakeys.noaa.gov/about/welcome.html?s=about

NOAA Office for Coastal Management. (2021). Coral Reefs. https://coast.noaa.gov/states/fast-facts/coralreefs.html\#: :text=Healthy coral reefs absorb 97, of erosion than those without.

Parasuraman, A. ; Zeithaml, V. A. ;, \& Berry, L. L. (1988). Servqual: A Multiple-Item Scale For Measuring Consumer Perc. Journal of Retailing; Spring, 64.

Pikkemaat, B., Bichler, B. F., \& Peters, M. (2020). Exploring the crowding-satisfaction relationship of skiers: the role of social behavior and experiences. Journal of Travel and Tourism Marketing, 37(8-9), 902-916. https://doi.org/10.1080/10548408.2020.1763229

Rasoolimanesh, S. M., Jaafar, M., Marzuki, A., \& Mohamad, D. (2016). How Visitor and Environmental Characteristics Influence Perceived Crowding. Asia Pacific Journal of Tourism Research, 21(9), 952-967. https://doi.org/10.1080/10941665.2015.1084348

Robinson, K., Burns, R., Pierskalla, C., \& Graefe, A. (2008). An aging population: relationships between socio-demographics, motivations and participation. 19-24.

Rosa, C. D., Larson, L. R., Collado, S., Cloutier, S., \& Profice, C. C. (2020). Gender Differences in Connection to Nature, Outdoor Preferences, and Nature-Based Recreation Among College Students in Brazil and the United States. Leisure Sciences. https://doi.org/10.1080/01490400.2020.1800538

Sánchez, J. J., Cerveny, L. K., Blahna, D. J., Valenzuela, F., \& Schlafmann, M. (2020). Recreation opportunities and human connections on public lands: constraints that limit recreation participation. 41-50.

Serrano Giné, D., Jurado Rota, J., Pérez Albert, M. Y., \& Bonfill Cerveró, C. (2018). The Beach Crowding Index: A Tool for Assessing Social Carrying Capacity of Vulnerable Beaches. The Professional Geographer, 70(3), 412-422. https://doi.org/10.1080/00330124.2017.1416300

Shafer, C. S., Inglis, G. J., Johnson, V. Y., \& Marshall, N. A. (1998). Visitor experiences and perceived conditions on day trips to the Great Barrier Reef. Tech. Rep. CRC Reef Res. Cent., January 2016. https://doi.org/10.13140/RG.2.1.3701.8648

Shelby, B., \& Heberlein, T. (1987). Carrying Capacity of Recreational Settings. Oregon State University Press.

Shelby, Bo, Heberlein, T. A., Vaske, J. J., \& Alfano, G. (1983). Expectations, preferences, and feeling crowded in recreation activities*. Leisure Sciences, 6(1), 1-14.

https://doi.org/10.1080/01490408309513019 
Torres-Matovelle, P., \& Molina-Molina, G. (2019). Evaluation of crowding and tourist satisfaction in the practice of humpback whale - watching, the case of Puerto López - Ecuador. Cuadernos de Gestion, 19(2), 185-208. https://doi.org/10.5295/cdg.180895pt

UNEP. (2018). The Coral Reef Economy: The business case for investment in the protection, preservation and enhancement of coral reef health. 36. www.unenvironment.org

UNWTO Tourism Dashboard. (2020). Global and Regional Tourism Performance: Purpose of Trip. https://www.unwto.org/global-and-regional-tourism-performance

Ursi, S., \& Towata, N. (2018). Environmental perception about marine and coastal ecosystems: Evaluation through a research instrument based on model of ecological values. Problems of Education in the 21st Century, 76(3), 393-405. https://doi.org/10.33225/pec/18.76.393

Uyarra, M. C., Watkinson, A. R., \& Côté, I. M. (2009). Managing dive tourism for the sustainable use of coral reefs: Validating diver perceptions of attractive site features. Environmental Management, 43(1), 1-16. https://doi.org/10.1007/s00267-008-9198-z

Vaske, J. J., Heesemann, L. M., Loomis, D. K., \& Cottrell, S. C. (2013). Measuring variability in encounter norms among scuba divers and snorkelers: An Application of the potential for conflict index2. Tourism in Marine Environments, 9(1-2), 69-80. https://doi.org/10.3727/154427313X13659574650027

Vaske, J. J., \& Shelby, L. B. (2008). Crowding as a Descriptive Indicator and an Evaluative Standard: Results from 30 Years of Research. Leisure Sciences, 30(2), 111-126. https://doi.org/10.1080/01490400701881341

von Ruschkowski, E., Burns, R., Arnberger, A., Smaldone, D., \& Meybin, J. (2013). Recreation Management in Parks and Protected Areas: A Comparative Study of Resource Managers Perceptions in Austria, Germany, and the United States. Journal of Park and Recreation Administration, 31(2), 95-114.

Wagar, J. A. (1964). The carrying capacity of wild lands for recreation. Forest Science, 10, 1-24.

Wilkinson, C. (2008). Status of coral reefs of the world: 2008. Global Coral Reef Monitoring Network and Reef and Rainforest Research Centre, 296.

Winter, P. L., Crano, W. D., Basáñez, T., \& Lamb, C. S. (2020). Equity in access to outdoor recreationinforming a sustainable future. Sustainability (Switzerland), 12(1), 1-16. https://doi.org/10.3390/SU12010124

World Tourism Organization (UNWTO). (2021). Methodological Notes to the Tourism Statistics Database, 2021 Edition. World Tourism Organization (UNWTO). https://doi.org/10.18111/9789284422517

Yoon, J. I., Kyle, G., Hsu, Y. C., \& Absher, J. (2021). Coping with crowded recreation settings: A crosscultural investigation. Journal of Leisure Research, 52(1), 1-21.

https://doi.org/10.1080/00222216.2020.1740630

Zehrer, A., \& Raich, F. (2016). The impact of perceived crowding on customer satisfaction. Journal of Hospitality and Tourism Management, 29, 88-98. https://doi.org/10.1016/j.jhtm.2016.06.007 
Ziegler, J. (2002). Recreating retirement: How will baby boomers reshape leisure in their 60s? In Parks a\& Recreation (pp. 56-61). 


\title{
Chapter 3
}

Paper 2

\author{
An Importance-Performance Analysis of Environmental Perceptions: Florida Keys \\ National Marine Sanctuary Recreationists and Resource Managers
}

\begin{abstract}
Healthy reefs, natural surroundings, clean coastal areas, underwater clarity, among others, are part of the ocean recreation experience of a recreationist. The primary purpose of this study is to examine an importance-performance analysis (IPA) of snorkelers, scuba divers and managers' environmental perceptions at Florida Keys National Marine Sanctuary. Online surveys were sent via Qualtrics to email addresses obtained from the state of Florida during summer of 2020. The IPA included a set of eight environmental items. The results showed that from the recreationists' perspective, managers should continue their ongoing efforts. Recreationists think that the availability of open mooring buoys and diving in uncrowded areas are a low priority, while experiencing adventure was considered a possible overkill. Although recreationists are slightly more satisfied than managers with seeing a healthy reef and diving on an area free of trash, managers believe these are the two items they should concentrate upon. Managers face complex challenges in their work, thus social science insights can aid decision-making processes and improve recreational experiences for snorkelers and scuba divers while still protecting the marine biodiversity in the Sanctuary.
\end{abstract}

Keywords: Importance-Performance Analysis, Environmental Perceptions, Marine Protected Areas, Tourism, Recreationists, Managers Input. 


\section{Introduction}

Healthy reefs, natural surroundings, clean coastal areas, and underwater clarity, among other aspects, are part of the ocean recreation experience of a recreationist (Coghlan, 2012; Urraya et al., 2008; Fitzsimmons, 2008; Urraya et al., 2005). Outdoor recreation and naturebased tourism in marine settings provide essential benefits to individuals, communities, and society; and at the same time, all these benefits have different contributions to sustainability (da Costa Cristiano et al., 2020; Winter et al., 2020a;). The definition of sustainable tourism by the World Tourism Organization (UNWTO) stated that: "Sustainable tourism development meets the needs of present tourists and host regions while protecting and enhancing opportunity for the future. It is envisaged as leading to management of all resources in such a way that economic, social, and aesthetic needs can be fulfilled while maintaining cultural integrity, essential ecological processes, biological diversity, and life support system” (UNESCO, 2005, p. 9). Nonetheless, it is important to recognize that it can be challenging to provide a sustainable recreation experience that satisfies the visitors without causing a negative impact in the marine environment. The complexity in outdoor recreation and nature-based tourism include factors such as equitable provision of opportunities, cultural variations in desired experiences, diverse perceptions and impacts of both nature and recreation (Winter et al., 2020a; Andrew et al., 2020; von Ruschkowski et al., 2013). It is common to hear that tourism and outdoor recreation are often qualified as double-edged activities, making socioeconomic contributions but also causing degradation of the environment (UNEP, 2018). Unfortunately, sandy coastal areas are naturally more vulnerable to recreation impacts due to interactions between wind, waves and sediments (Priskin, 2003). Thus, the intensity of recreation impact is affected by a combination of factors such as use level, type and behavior of use, season of use and the environmental conditions of the area (Priskin, 2003; Krieger \& Chadwick, 2013). 
It is crucial to find a balance between the benefits and pressures that human activity can cause in a marine protected area. Significant amounts of people visit the Florida Keys National Marine Sanctuary to participate in ocean recreation activities such as fishing, diving, snorkeling, general boating and others. The coral reefs in this Sanctuary have unique biodiversity and provide important ecological ecosystem services (Camp \& Fraser, 2012). Thus, a better understanding of visitors' perceptions and their patterns can increase sustainability of valuable ecosystem services in this area and potential economic contributions (Burns et al., 2020a; Day, 2008; Hansen, 2015). The primary purpose of this study is to examine an importanceperformance analysis of snorkelers, scuba divers and managers' environmental perceptions at Florida Keys National Marine Sanctuary. Specific objectives of this paper include: 1) describing the sample of users and their socio-demographics; 2) examining an importance-performance analysis from the recreationists perspective; and 3) examining an importance-performance analysis from the managers perspective. This study is part of a larger scale project called National Marine Sanctuaries Visitor Counting Process (NMS-COUNT) (Burns et al., 2020a) which will be used to aid NOAA management decisions regarding recreational use in national marine sanctuaries.

\section{Literature Review}

Importance-Performance Analysis (IPA) in Ocean Recreation

Managers in marine protected areas often use social science and management tools to make decisions that are sustainable and ecologically balanced while keeping visitor satisfaction levels high. Martilla \& James (1977) created an Importance-Performance Analysis (IPA), which was an easily-applied technique for measuring attribute importance and performance in customer satisfaction (Figure 1). IPA can yield important insights into the aspects that need more attention 
as well as the ones that may be consuming too many resources. The popularity of importanceperformance analysis has stimulated discussion and research on the validity and reliability of this technique (Oh, 2001). According to Guadagnolo (1985), each of the quadrants explain where the factors are falling into and the possible actions that the managers could take:

Quadrant 1 -Concentrate here: the respondents view these features as important, but the agency received low ratings for their performance. These features require the greatest attention since these are important enough to impact upon the quality of the experience.

Quadrant 2-Keep up the good work: it means that the respondents rated the management agency as performing well. This quadrant has the highest ratings on importance and performance. Therefore, the responsibility is to make sure that these important features remain in this quadrant.

Quadrant 3 - Low priority: the features in this quadrant have low ratings on both importance and performance. This quadrant requires little or no attention since the respondents did not rate these items as important.

Quadrant 4-Possible overkill: This quadrant received low importance ratings and high performance ratings. It suggests that less attention and resources could be spent since the respondent do not consider these features as important. 
Figure 1. Importance-Performance Analysis Grid adapted from Martilla \& James (1977)

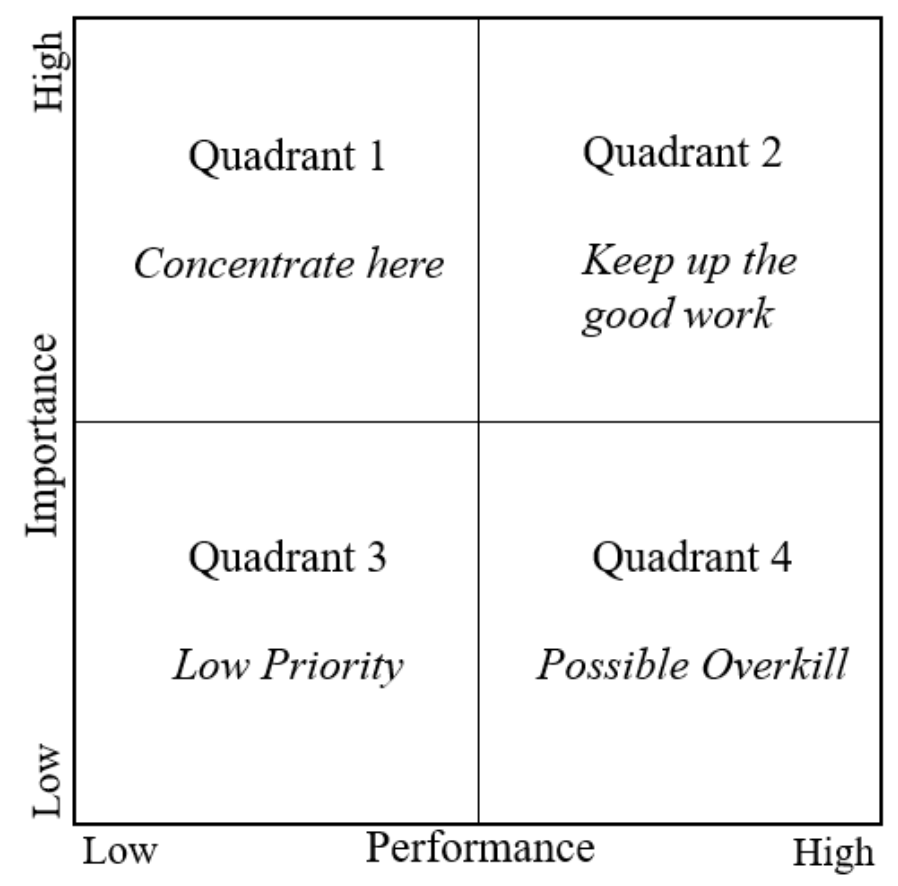

The IPA technique was originally created to further the development of effective marketing programs. However, managers in the outdoor recreation and tourism sector have used IPA to assess the competitive position of a product, service, or tourism destination; although they also formulate appropriate strategies for achieving a competitive advantage over their competitors (Dwyer et al., 2016; Deng, 2007; Guizzardi \& Stacchini, 2017). IPA studies can also be specifically found in coral reef and ocean recreation research areas (Fiore et al., 2020; Coghlan, 2012; Ziegler, 2012; Mimbs et al., 2020). Managers from marine protected areas can benefit from this analysis because the presentation of the results on the importance-performance grid facilitates management interpretation of the data and increases their usefulness in the decision-making process (Martilla \& James, 1977). In other words, IPA allows managers to develop action strategies without being versed in complicated statistical analysis (Guadagnolo, 1985). 


\section{$\underline{\text { Importance-Performance Analysis for Environmental Perceptions }}$}

The IPA items that were analyzed in this study had the purpose of measuring snorkelers' and scuba divers' importance and satisfaction (i.e. performance) levels for recreating in a healthy marine environment. Scuba diving in the Florida Keys is a form of marine-based tourism that contributes over $\$ 1.2$ billion annually to the tourism industry (Paterson et al., 2012; Camp \& Fraser, 2012). However, there is a great variety of natural and anthropogenic stressors affecting reefs, such as diving and snorkeling. Impacts of intensive diving tourism on coral reefs remain poorly understood, especially in Florida Keys (Krieger \& Chadwick, 2013). Divers collide with reefs and produce short- and longer-term damage to corals while recreating (Urraya et al., 2008; Krieger \& Chadwick, 2013; Camp \& Fraser, 2012). They can cause this by walking on them, kicking them with fins, smashing them during a loss of buoyancy control, or by stirring up sand on the ocean floor; on the other hand, skilled divers can move through the water with proper buoyancy and fin techniques mitigating the negative impacts (Anderson \& Loomis, 2011). Environmental education and interpretive methods for snorkelers and scuba divers can provide positive effects on their behaviors (Camp \& Fraser, 2012). Research has shown that divers who received pre-dive ecological briefings are likely to cause significantly less coral damage than those who did not, and divers with cameras are likely to cause more damage (Krieger \& Chadwick, 2013). All these basic rules of behavior are important to coral reefs health and user satisfaction (Anderson \& Loomis, 2011).

Ursi and Towata (2018) emphasized that different people might have different reactions to the same environment; therefore, environmental values and attitudes are an important part of environmental perception in marine settings (Giglio \& Schiavetti, 2015; Oigman-Pszczol, 2007; Alessa et al., 2003). According to these authors, these attitudes can be defined as "the collection 
of beliefs and behavioral intentions a person holds regarding environmentally related activities or issues" (Ursi \& Towata, 2018, p. 394). Research in this field emphasizes how important it is to understand how individuals are distributed on a biocentric to an anthropocentric continuum (Ursi \& Towata, 2018; van Riper et al., 2020; Wynveen et al., 2015; Wynveen et al., 2013). Satisfaction levels while recreating in a healthy marine environment can be influenced by different variables. The analysis for this study included the following variables: 1) seeing a healthy reef; 2) diving in an uncrowded area; 3) experiencing good underwater clarity; 4) experiencing natural surroundings; 5) experiencing adventure; 6) experiencing a clean reef; 7) availability of an open mooring buoy; and 8) diving on an area free of discarded fishing traps, line, or tackle. These environmental items are similar to the environmental inputs and outputs that Buckley (2003) defined as part of ecotourism characteristics. The inputs are the natural and associated cultural features in a particular geographic place which serve as attractions for tourists, while the outputs are the net costs or benefits for the natural and social environment (Buckley, 2003).

\section{Methodology}

Study Area

Florida Keys National Marine Sanctuary was designated on November 16, 1990 and it protects 2,900 square nautical miles of waters. The boundaries of the sanctuary are from south of Miami, Florida to the Dry Tortugas, although it excludes Dry Tortugas National Park (Figure 2). This sanctuary protects a coral barrier reef, extensive seagrass beds, man-grove-fringed islands, more than 6,000 species of marine life, as well as historical and archeological heritage such as shipwrecks (NOAA, 2021). Florida Keys National Marine Sanctuary is part of the National 
Marine Sanctuary System and is administered by the National Oceanic and Atmospheric Administration (NOAA) Office of National Marine Sanctuaries (ONMS). NOAA defines National Marine Sanctuaries as protected waters that include habitats such as rocky reefs, kelp forests, deep-sea canyons, and underwater archaeological sites (NOAA, 2021). The National Marine Sanctuaries Act established Florida Keys National Marine Sanctuary for the purpose of managing and protecting the conservation, recreational, ecological, historical, scientific, educational, cultural, archaeological or aesthetic resources and qualities of a national marine sanctuary (NMSA, 1992).

\section{Figure 2. Florida Keys National Marine Sanctuary}

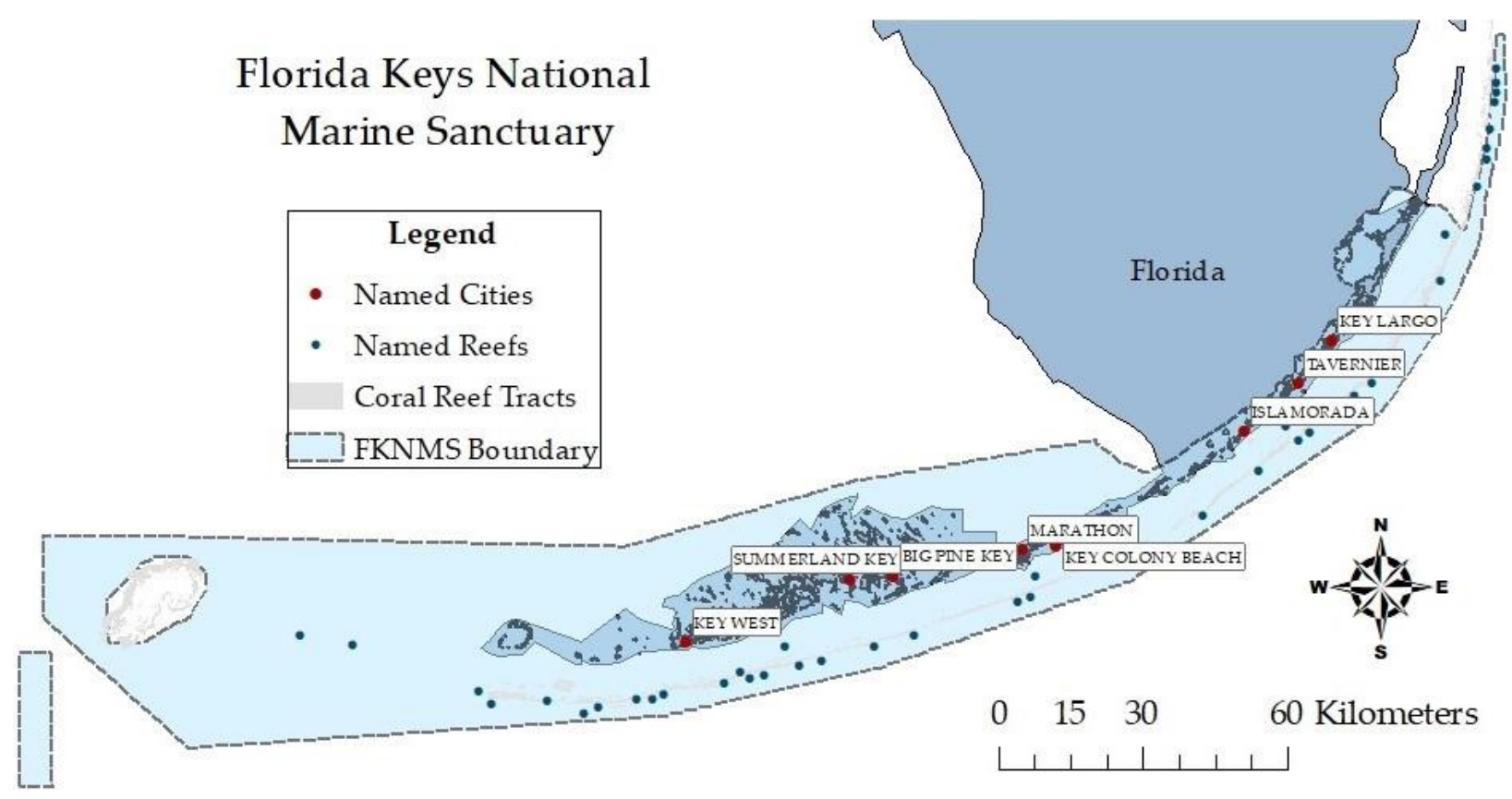

\section{$\underline{\text { Data Collection }}$}

The survey instrument used for this study was originally designed for visitor use information related to SCUBA divers and snorkelers in Florida Keys National Marine Sanctuary (Appendix A) as part of the NMS-COUNT project (Burns et al., 2020a). The questions selected from the survey instrument were designed to measure the users' perceptions of importance and 
performance of eight environmental items. This study followed the original importance-

performance analysis technique from Martilla \& James (1977). In this study, the importance scores were collected using a 5-point scale with increasing values meaning higher importance level (i.e. 1 being not at all important and 5 being extremely important). Performance scores were similarly collected using a 5-point scale with increasing values meaning higher satisfaction level (i.e. 1 being not at all satisfied and 5 being extremely satisfied). An Importance-

Performance Analysis was done following the technique created by Martilla \& James (1977). Finally, basic socio-demographics, such as age, gender, ethnicity, race, education, income and residence, were also collected and examined. The questions selected from the survey instrument can be seen in Table 1.

Table 1. Questions selected from survey instrument for use in analysis in this study shown with response scale.

\begin{tabular}{ll}
\hline \hline Questions & Answers \\
How important was it to you to do each of the & Seeing a healthy reef \\
following during your most recent 2019 trip to & Diving in an uncrowded area \\
Florida Keys National Marine Sanctuary? & Experiencing good underwater clarity \\
& Experiencing natural surroundings \\
$1=$ Not at all Important & Experiencing adventure \\
$5=$ Extremely Important & Experiencing a clean reef \\
& Availability of an open mooring buoy \\
& Diving on an area free of discarded fishing \\
& traps, line, or tackle
\end{tabular}

How satisfied were you with each of the following during your most recent trip to the Florida Keys

Seeing a healthy reef National Marine Sanctuary?

Diving in an uncrowded area

Experiencing good underwater clarity Experiencing natural surroundings

$1=$ Not at all Satisfied

$5=$ Extremely Satisfied

Experiencing adventure

Experiencing a clean reef

Availability of an open mooring buoy

Diving on an area free of discarded fishing traps, line, or tackle

While the original aim for this study was to collect data through in-person interviews in Florida Keys National Marine Sanctuary, the ongoing COVID-19 pandemic precluded in-person 
activities. Accordingly, a database of active recreationists who hold various Florida outdoor recreation licenses (e.g., fishing licenses, boating licenses, diving licenses) was used to obtain a sample for the study. There were 380 surveys collected and the response rate was $73 \%$. The survey distribution followed the Dillman method (Dillman \& Bowker, 2001), which describes the most desirable web surveying practices for contacting and reminding respondents about survey participation. After the first personalized email with the survey link, two weekly reminder emails were sent to the non-respondents to increase the likelihood of response. The respondents were able to skip questions while taking the survey on Qualtrics.

\section{Results}

$\underline{\text { Sample Profile }}$

The socio-demographic profile of the respondents included their residence status, age, sex, race, ethnicity, education and income levels (Table 2). The results showed that a majority (74.4\%) of the respondents were visitors, while $17.4 \%$ were permanent residents of Monroe County, Florida and $8.1 \%$ were seasonal residents of Monroe County. The average age of the respondents was 52.9 years and the majority were male (77.3\%). Regarding race and ethnicity, 91.8\% classified themselves as white and $82.6 \%$ as non-Hispanic. More than half of the respondents $(61.5 \%)$ had at least a college graduate completed and a considerable number $(63.8 \%)$ indicated an annual household income of over $\$ 100,001$. The results showed that only $8.7 \%$ of the respondents have visited the Florida Keys once, while $75 \%$ of the respondents have visited the area more than once. Therefore, the majority of the respondents are considered to be return visitors. 
Table 2. Socio-demographic profile of survey respondents, shown with frequency and percentage of responses for each optional survey question.

\begin{tabular}{|c|c|c|c|c|}
\hline Socio-demographic & Profile & $\begin{array}{c}\text { Valid } \\
\text { Percent }(\%) \\
\end{array}$ & Frequency & $N$ \\
\hline \multirow[t]{3}{*}{ Residence } & Permanent resident & 17.4 & 30 & \multirow[t]{3}{*}{172} \\
\hline & Seasonal resident & 8.1 & 14 & \\
\hline & Visitor & 74.4 & 128 & \\
\hline \multirow[t]{2}{*}{ Sex } & Male & 77.3 & 133 & \multirow[t]{2}{*}{172} \\
\hline & Female & 22.7 & 39 & \\
\hline \multirow[t]{3}{*}{ Age Recoded } & 30 or younger & 4.3 & 7 & \multirow[t]{3}{*}{163} \\
\hline & $31-50$ & 29.4 & 48 & \\
\hline & 51 and over & 66.3 & 108 & \\
\hline \multirow[t]{2}{*}{ Ethnicity } & Hispanic & 17.4 & 30 & \multirow[t]{2}{*}{172} \\
\hline & Non-Hispanic & 82.6 & 142 & \\
\hline \multirow[t]{2}{*}{ Race Recoded } & White & 91.8 & 157 & \multirow[t]{2}{*}{171} \\
\hline & Non-White & 8.2 & 14 & \\
\hline \multirow[t]{4}{*}{ Education } & High school graduate & 8.9 & 15 & \multirow[t]{4}{*}{169} \\
\hline & Some college & 29.6 & 50 & \\
\hline & College graduate & 33.7 & 57 & \\
\hline & Post graduate & 27.8 & 47 & \\
\hline \multirow[t]{3}{*}{ Income Recoded } & Under $\$ 50,000$ & 8.8 & 14 & \multirow[t]{3}{*}{160} \\
\hline & $\$ 50,001-\$ 100,000$ & 27.5 & 44 & \\
\hline & Over $\$ 100,001$ & 63.8 & 102 & \\
\hline
\end{tabular}

Importance-Performance Analysis from a Recreationist Perspective

Considering the most recent 2019 trip to Florida Keys National Marine Sanctuary, the respondents rated on a scale from 1 to 5 , with 1 being not at all important and 5 being extremely important, how important was to them each of the eight environmental items in Table 3 . The item experiencing a clean reef $($ mean $=4.5)$ was rated as the most important one and the item diving in an uncrowded area $($ mean $=3.7)$ was rated as the least important. Diving on an area free of discarded fishing traps, line, or tackle and experiencing natural surroundings were also rated with high importance scores $($ mean $=4.4)$. 
Table 3. Recreationists' Importance Levels for Environmental Items

\begin{tabular}{lccc}
\hline \hline \multicolumn{1}{c}{ Item } & $M$ & $S D$ & $S E$ \\
\hline 1. Seeing a healthy reef & 4.34 & 0.83 & 0.07 \\
2. Diving in an uncrowded area & 3.74 & 1.07 & 0.08 \\
3. Experiencing good underwater clarity & 4.24 & 0.78 & 0.06 \\
4. Experiencing natural surroundings & 4.37 & 0.75 & 0.06 \\
5. Experiencing adventure & 3.96 & 1.08 & 0.08 \\
6. Experiencing a clean reef & 4.54 & 0.71 & 0.06 \\
7. Availability of an open mooring buoy & 3.84 & 1.19 & 0.09 \\
8. Diving on an area free of discarded fishing traps, line, or tackle & 4.40 & 0.90 & 0.07 \\
\hline
\end{tabular}
Note: $M, S D, S E$ represent mean, standard deviation, standard error of mean and total responses, respectively.

The IPA technique measures performance with satisfaction. In this study, the respondents rated the environmental items on a scale from 1 to 5 , with 1 being not at all satisfied and 5 being extremely satisfied, related to their most recent 2019 trip to Florida Keys National Marine Sanctuary (Table 4). The item experiencing natural surroundings $($ mean $=3.80)$ was rated with the highest performance score and experiencing adventure (mean $=3.73)$ also had a high performance score. Availability of an open mooring buoy (mean = 3.19) and seeing a healthy reef $($ mean $=3.20)$ were the items rated with the lowest performance score.

Table 4. Recreationists' Satisfaction Levels for Environmental Items

\begin{tabular}{lccc}
\hline \hline \multicolumn{1}{c}{ Item } & $M$ & $S D$ & $S E$ \\
\hline 1. Seeing a healthy reef & 3.20 & 1.06 & 0.08 \\
2. Diving in an uncrowded area & 3.30 & 1.01 & 0.08 \\
3. Experiencing good underwater clarity & 3.45 & 0.96 & 0.08 \\
4. Experiencing natural surroundings & 3.80 & 0.86 & 0.07 \\
5. Experiencing adventure & 3.73 & 0.87 & 0.07 \\
6. Experiencing a clean reef & 3.42 & 1.06 & 0.08 \\
7. Availability of an open mooring buoy & 3.19 & 1.11 & 0.09 \\
8. Diving on an area free of discarded fishing traps, line, or tackle & 3.43 & 1.14 & 0.09
\end{tabular}

Note: M, SD, SE represent mean, standard deviation, standard error of mean and total responses, respectively. 
There are two different methods to create importance-performance grids. The first grid created used middles lines that showed 2.5 as the mid-point of the scale (Figure 3). In this grid the eight environmental items fell into the quadrant "Keep Up The Good Work".

Figure 3. Recreationists IPA general grid for environmental items

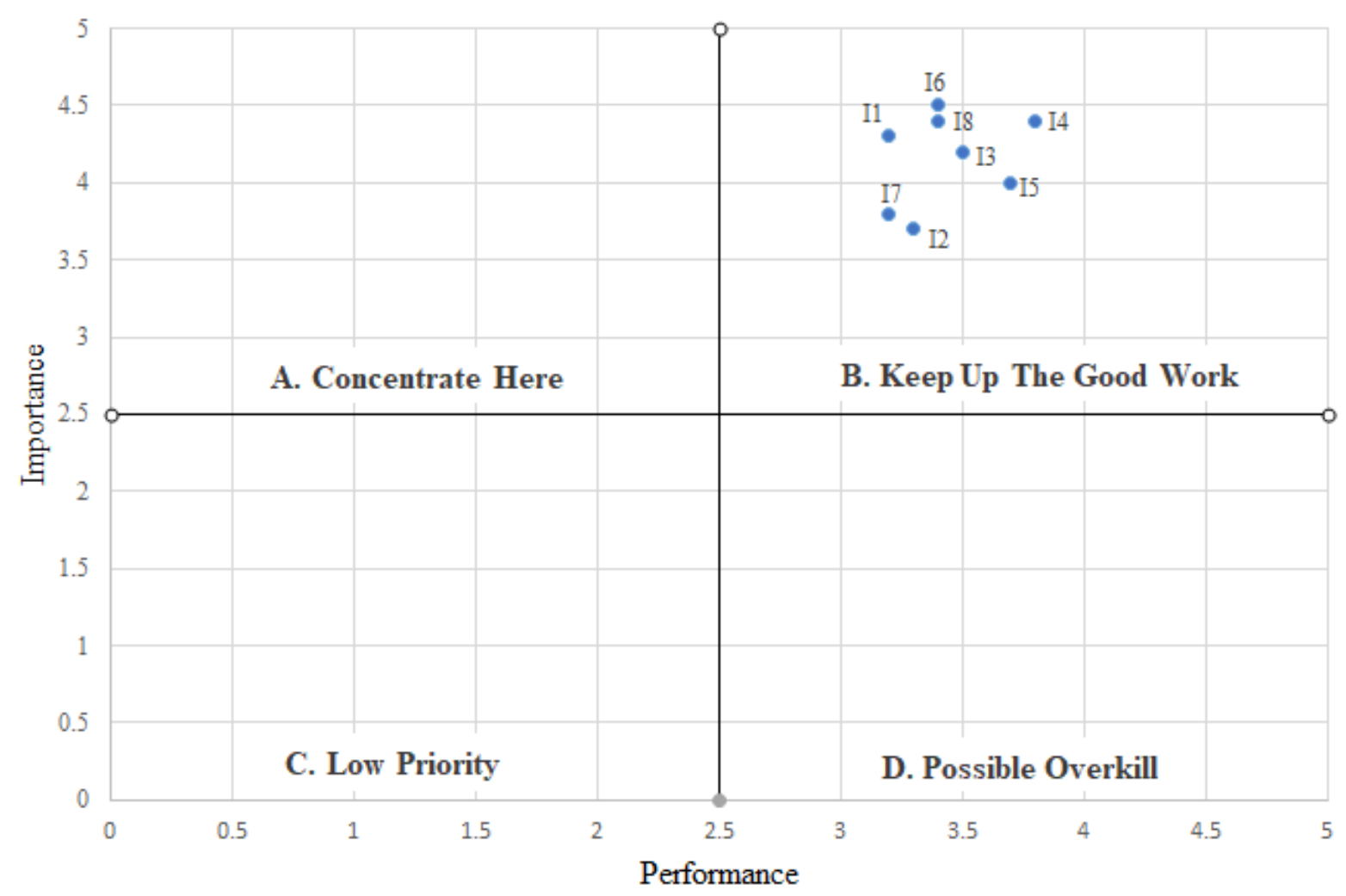

Note: Middle lines show 2.5 as the mid-point of scale. II - Seeing a healthy reef, I2 - Diving in an uncrowded area, I3 - Experiencing good underwater clarity, I4 - Experiencing natural surroundings, I5 - Experiencing adventure, I6 - Experiencing a clean reef, I7 - Availability of an open mooring buoy, I8 - Diving on an area free of discarded fishing traps, line, or tackle.

The second grid created used middles lines that showed the median as the mid-point of the scale (Figure 4). In this grid the environmental items fell into different quadrants. The first quadrant is "Concentrate Here", this means that the features require the greatest attention since these are important enough to impact upon the quality of the experience. It is important to emphasize that some items fell right into the middle of two quadrants. This is the case of seeing 
a healthy reef, which fell into the quadrant "Concentrate Here" and "Low Priority". The second quadrant is "Keep Up The Good Work", it has the highest ratings on importance and performance, meaning the management agency is performing well. The item that fell into the second quadrant is experiencing natural surroundings. However, there are two items that fell right in between "Keep Up The Good Work" and "Concentrate Here"; these items were experiencing a clean reef and diving on an area free of discarded fishing traps, line, or tackle.

The third quadrant is "Low Priority", the features in this quadrant have low ratings on both importance and performance. This quadrant suggests little or no attention is required, since the respondents did not rate these items as important. The features that fell into the third quadrant are diving in an uncrowded area and availability of an open mooring buoy. The fourth and last quadrant is "Possible Overkill", it received low importance ratings and high performance ratings. It suggests that less attention and resources could be spent since the respondents do not consider these features as important. The features that fell into the fourth quadrant are experiencing good underwater clarity and experiencing adventure. 
Figure 4. Recreationists IPA grid for environmental items

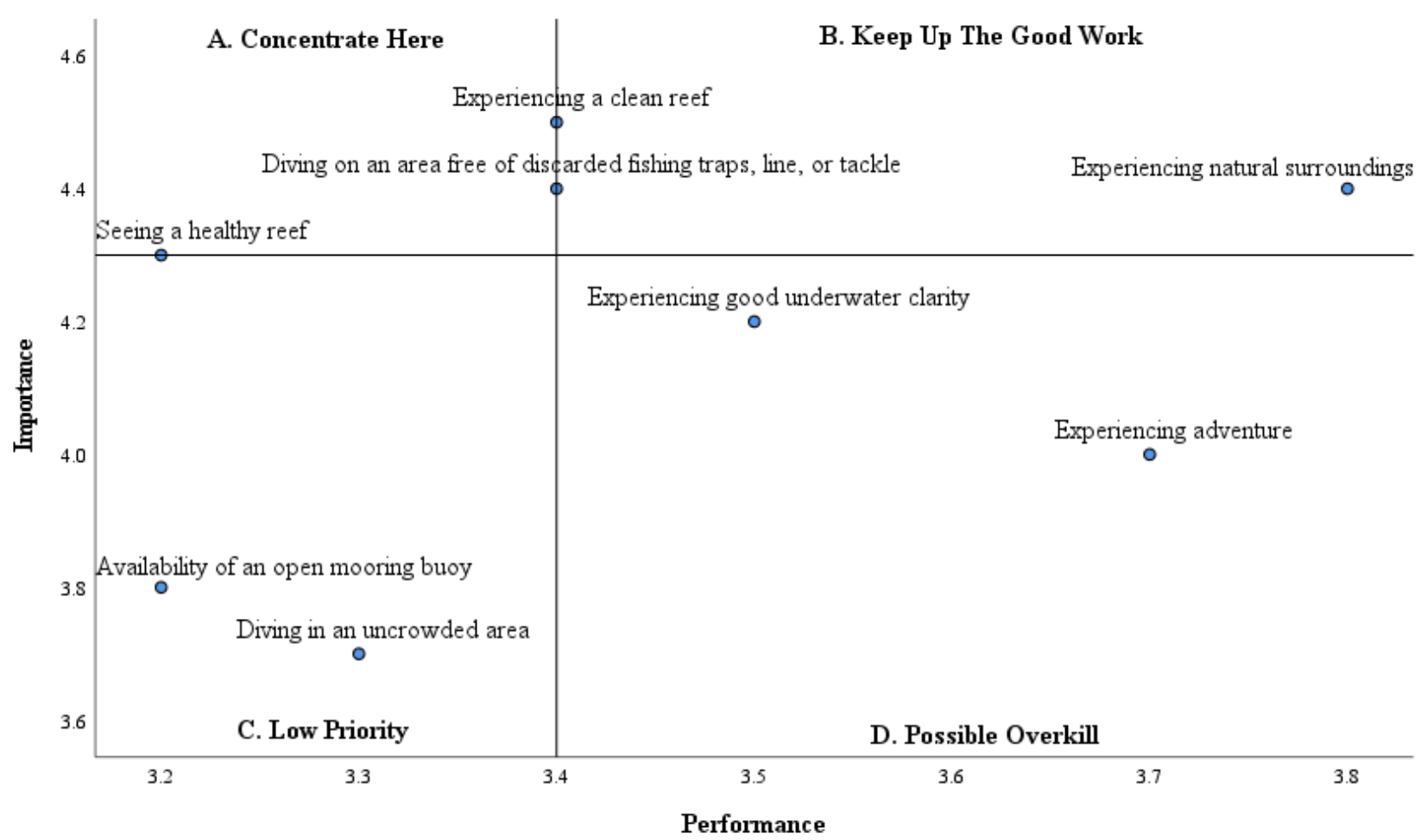

Note: Middle lines show the median.

$\underline{\text { Importance-Performance Analysis from a Manager Perspective }}$

The managers had the opportunity to rate the same importance-performance items that were rated by the recreationists in Florida Keys National Marine Sanctuary. Seeing a healthy reef was rated as the most important (mean $=4.71)$ item for the managers and at the same time, it was rated with the lowest performance score $($ mean $=2.43)$. The means of importance and performance scores rated by the managers are shown in Table 5.

Table 5. Managers Means of Importance and Performance Items.

\begin{tabular}{lcc}
\hline \hline \multicolumn{1}{c}{ Item } & Importance Mean & Performance Mean \\
\hline 1. Seeing a healthy reef & 4.71 & 2.43 \\
2. Diving in an uncrowded area & 4.14 & 3.00 \\
3. Experiencing good underwater clarity & 4.14 & 3.57 \\
4. Experiencing natural surroundings & 4.71 & 3.71
\end{tabular}


5. Experiencing adventure

6. Experiencing a clean reef

7. Availability of an open mooring buoy

8. Diving on an area free of discarded fishing traps, line, or tackle

The first grid created with the managers perceptions used middles lines that showed 2.5 as the mid-point of the scale (Figure 5). The majority of the items fell into the quadrant "Keep Up The Good Work", expect for the item seeing a healthy reef, that feel into the quadrant "Concentrate Here".

Figure 5. Managers IPA general grid for environmental items

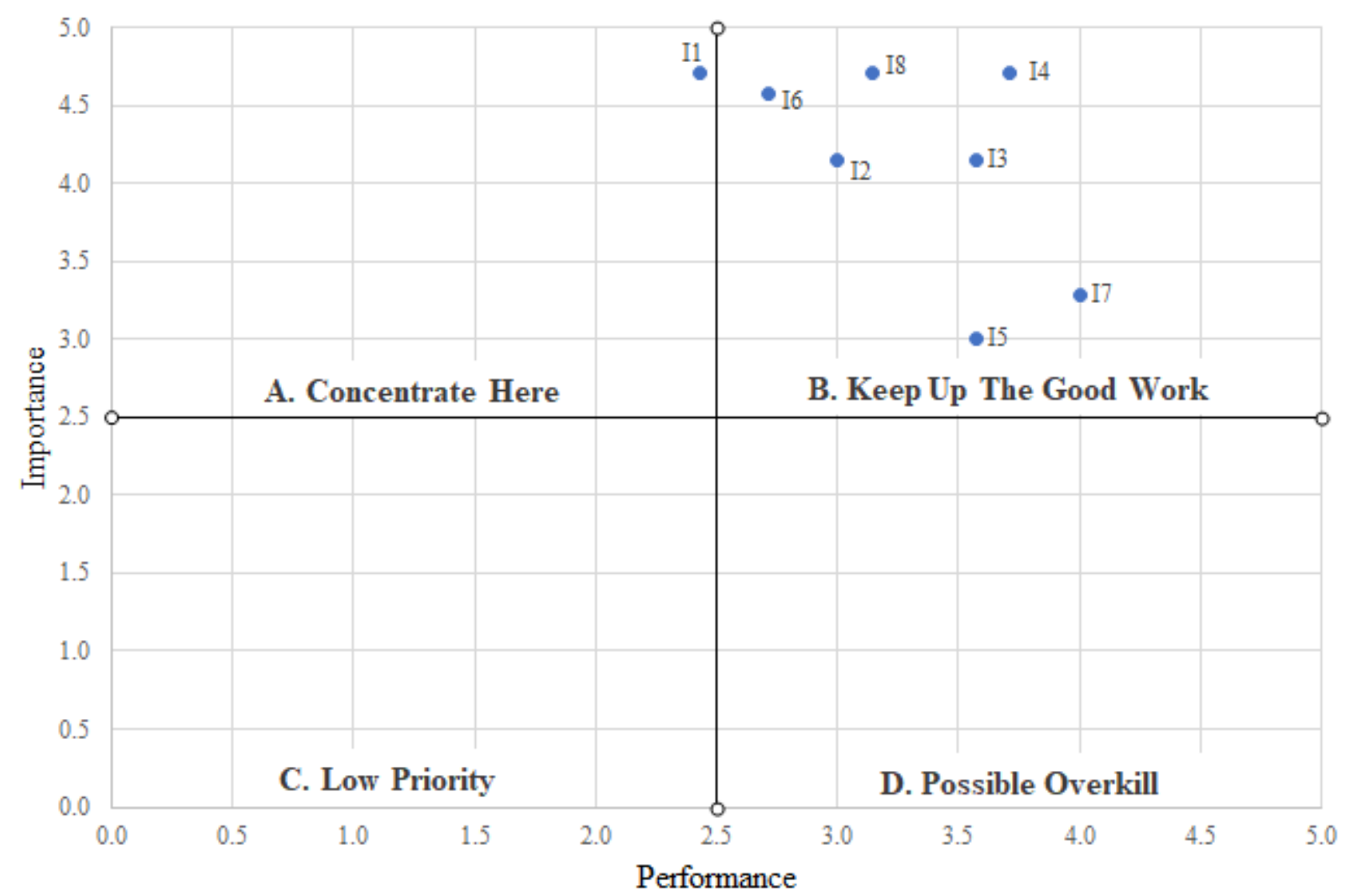

Note: Middle lines show 2.5 as the mid-point of scale. II - Seeing a healthy reef, I2 - Diving in an uncrowded area, I3 - Experiencing good underwater clarity, I4 - Experiencing natural surroundings, I5 - Experiencing adventure, I6 - Experiencing a clean reef, I7 - Availability of an open mooring buoy, I8 - Diving on an area free of discarded fishing traps, line, or tackle. 
The second grid created with the managers perceptions used middles lines that showed the median as the mid-point of the scale (Figure 6). In this grid the environmental items feel into different quadrants. The first quadrant is "Concentrate Here" and the items that fell into this quadrant are seeing a healthy reef and diving on an area free of discarded fishing traps, lines or tackle. Experiencing a clean reef fell right into the middle of "Concentrate Here" and "Low Priority". The second quadrant is "Keep Up The Good Work" and the only item that fell into this quadrant was experiencing natural surroundings. The third quadrant is "Low Priority" and the item that fell into this quadrant was diving in an uncrowded area. However, there were some items that fell right into the middle of "Low Priority" and "Possible Overkill", which were experiencing adventure and experiencing good underwater clarity. The fourth quadrant is "Possible Overkill" and the item in this quadrant was availability of an open mooring buoy.

Figure 6. Managers IPA grid for environmental items

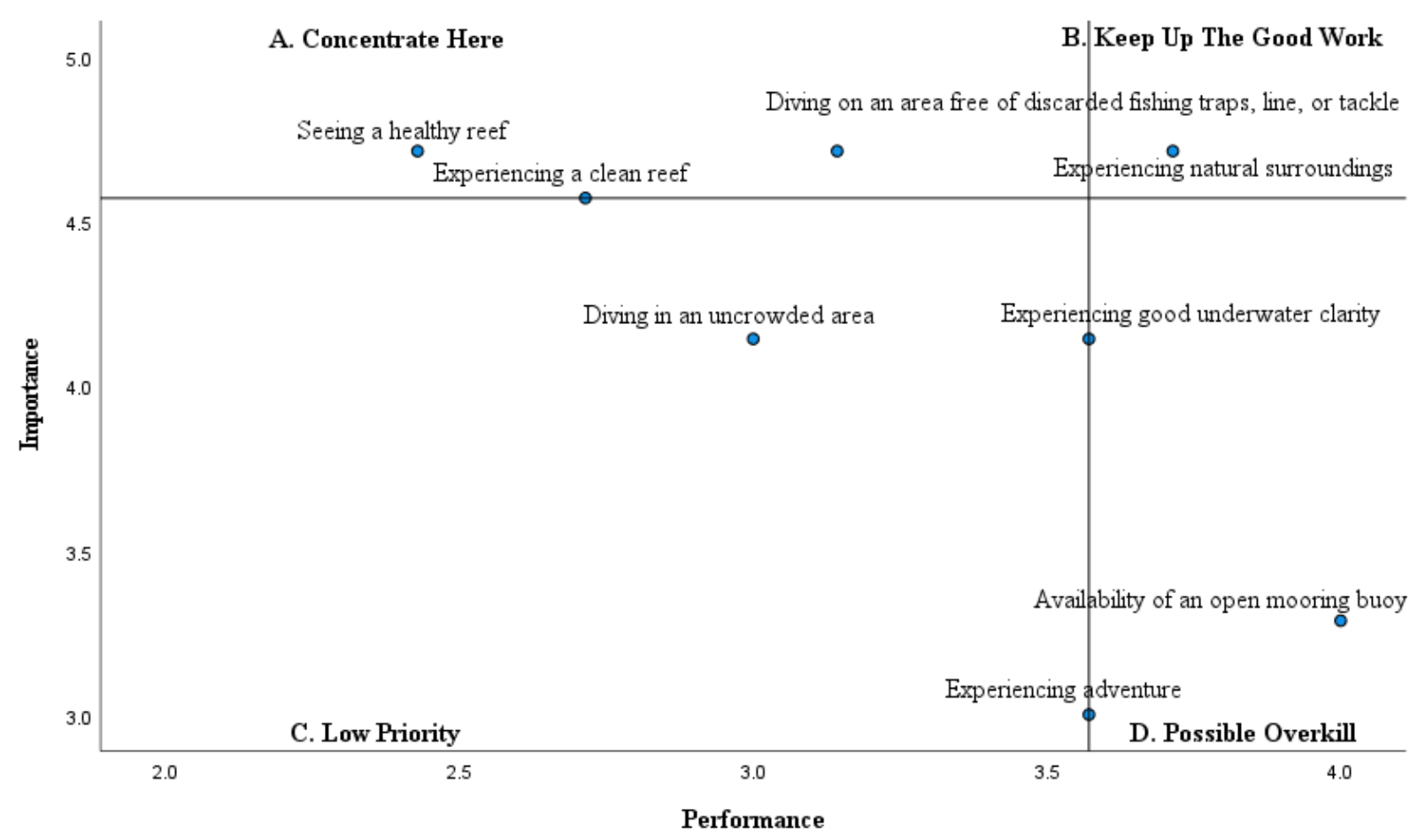

Note: Middle lines show the median. 
Finally, figure 7 shows a merged graphic of the responses from the recreationists and the managers. This graphic shows 2.5 as the mid-point of the scale. In this graphic the blue dots are responses from the managers and the red triangles are the responses from the recreationists.

Overall, the recreationists are slightly more satisfied than the managers with the majority of the items.

Figure 7. Merged IPA with recreationists and managers perceptions

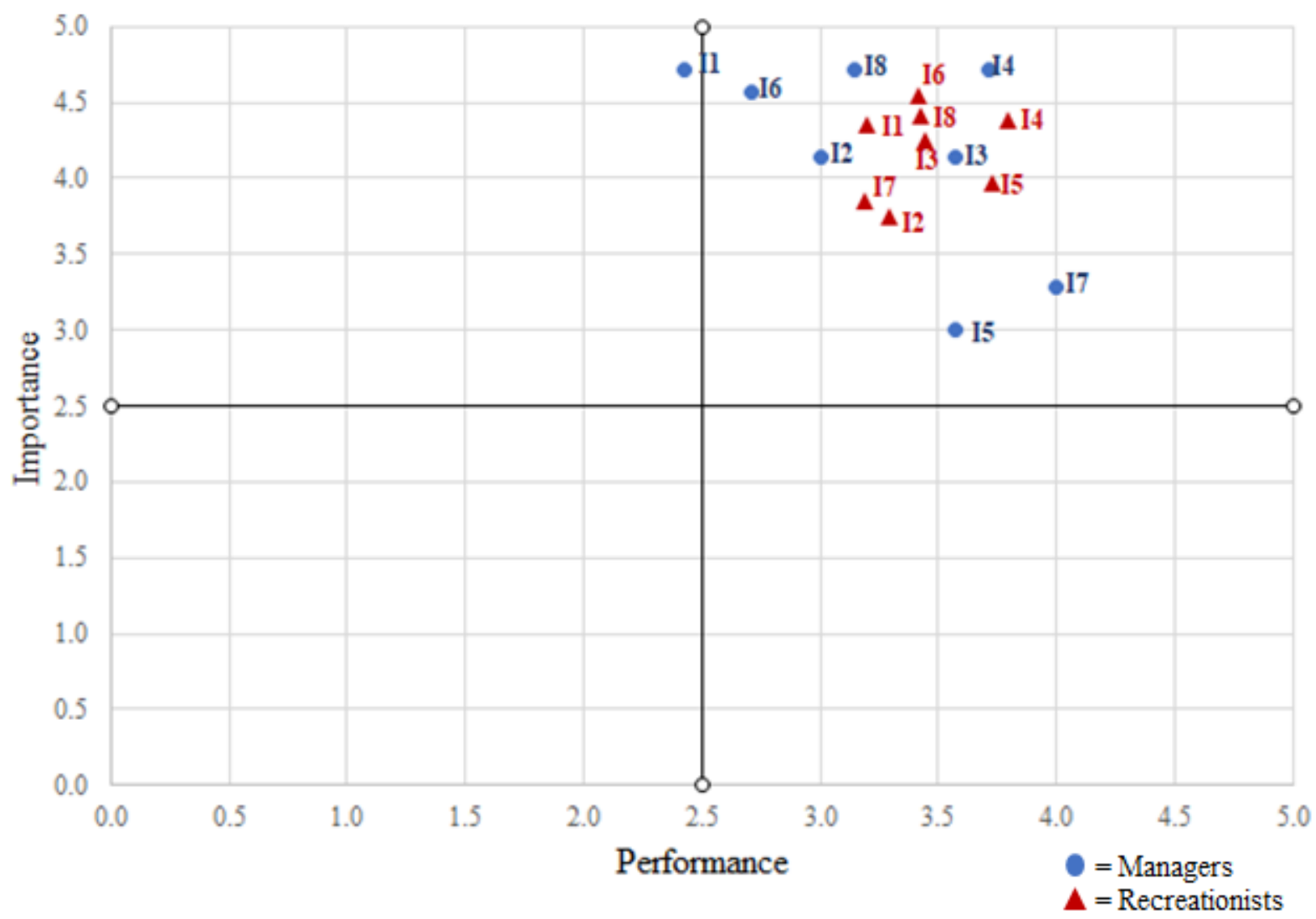

Note: Middle lines show 2.5 as the mid-point of scale. II - Seeing a healthy reef, I2 - Diving in an uncrowded area, I3 - Experiencing good underwater clarity, I4 - Experiencing natural surroundings, I5 - Experiencing adventure, I6 - Experiencing a clean reef, I7 - Availability of an open mooring buoy, I8 - Diving on an area free of discarded fishing traps, line, or tackle. 


\section{Discussion}

The socio-demographic profile of the respondents in this study included their residence status, age, sex, race, ethnicity, education and income levels. The respondents were predominantly well-educated and affluent white males. Their average age was 53 years old. There was a considerable high number of respondents that indicated an annual household income of over $\$ 100,001$. The data of this study showed there is an underrepresentation of minority populations such as Hispanic, Black, American Indian, among others, in Florida Keys National Marine Sanctuary. People with low household incomes are also not likely to visit the Sanctuary, hence, managers could take in consideration the possibilities of providing opportunities for a wider range of visitors from different socio-demographic backgrounds to make the destination more accessible for everyone. Providing equity and diversity related to recreation opportunities can bring multiple benefits for underserved populations, natural resource management agencies and other stakeholders (Winter et al., 2020b).

It is important to emphasize that the general IPA grids showed that the managers in Florida Keys National Marine Sanctuary are doing a good job overall and they should keep up the good work. The data in the grids that used middle lines as the median indicated the specific quadrant where each of the items fell into. The IPA brought the opportunity of understanding which are the items that need more attention in order to keep the visitor satisfaction high while also taking care of the marine natural resources. Seeing a healthy reef was the item with the highest importance and the lowest performance score rated by the local managers. The recreationists rated this item similarly however, the recreationists are slightly more satisfied than the managers. It is possible that the recreationists have less knowledge on how to evaluate a healthy reef than a local manager (Anderson \& Loomis; 2012; Alessa et al., 2003). The managers 
need to invest strong efforts in this feature since it requires the greatest attention out of all the eight items listed. Experiencing a clean reef had similar rating scores than seeing a healthy reef. The main difference between these two items is that experiencing a clean reef involves the presence of trash as a critical variable (Harris et al., 2021), while seeing a healthy reef can be visually harder to identify for the recreationists depending on their specialization level (Anderson \& Loomis; 2012). Managers need to keep concentrating on maintaining a clean reef since it affects the recreationists' experience. Nonetheless, visitors are more satisfied than what the managers are with this item.

Diving on an area free of discarded fishing traps, line, or tackle is an important factor for snorkeling and scuba diving because this type of trash can settle on reefs preventing the sunlight required for photosynthesis and kill the reef organisms (EI-Naggar, 2020). Managers need to concentrate in this item since it has high importance scores but lower performance scores. The recreationists still have slightly higher satisfaction rates than managers. Plastic pollution is a major anthropogenic stressor on the marine environment thus large-scale behavioral, economic and political changes coming are needed to tackle this issue (Stafford \& Jones, 2019). Experiencing natural surroundings was the only item that fell into the category "Keep Up The Good Work" in both recreationists and managers' importance-performance grids, which means this item is important and they are satisfied with it. This is a popular item in the outdoor recreation literature because many studies have shown this is a strong motivation and main reason why people decide to recreate outdoors (Buckley, 2012; Burns et al., 2020b).

Diving in an uncrowded area was the only item that the recreationists and managers rated as a low priority. This means that this item requires little or no attention since it has low ratings on both importance and performance. A crowded area can be considered as a variable that 
influences satisfaction in the outdoor recreation literature (Burns et al., 2018; Burns et al., 2021). There is no need for managers to take actions about crowding now. This does not mean that crowding cannot be a problem in the future, but at this time there are more important items to consider when taking management decisions. On the other hand, there is also a possibility that recreationists can have increased feelings of safety while snorkeling and scuba diving with more people around them since solo diving is not a common practice. Availability of an open mooring buoy was a low priority for recreationists and a possible overkill for managers. Mooring buoys use has reduced anchor damage to reefs but it has also led to elevated numbers of divers in the water around popular reefs (Krieger \& Chadwick, 2012; Shivlani \& Suman, 2000). Less attention and resources could be spent in this item since the recreationists did not rate it with high levels of importance.

Experiencing good underwater clarity was considered possible overkill for recreationists, which means that it has high performance ratings but low importance ratings. Managers think it could be possible overkill and a low priority item at the same time. One of the managers gave feedback to the team about how water quality is considered to be extremely important for managers, but not the underwater clarity necessarily. Underwater clarity and visibility while snorkeling or scuba diving depend on light penetration, biological species and particulates such as sand and silt (Rossier, 1995). Experiencing adventure was not rated with high importance level scores by neither recreationists nor managers. This item was a possible overkill for recreationists, but the managers' IPA grid also considered it a low priority. Experiencing adventure can be more important in some recreational activities than others. This is traditionally an important factor for the recreational activities within the adventure tourism field such as climbing and mountaineering, whitewater rafting and kayaking, surfing and sailboarding, etc. 
(Burkley, 2012). The recreationists at this Sanctuary might have other motivations such as spending time with friends and family, getting out of the routine, or seeing a beautiful scenery.

As a suggestion for future research directions in this field, we recommend studies that identify the environmental perceptions between recreationists with biocentric values and recreationists with anthropocentric values. Future studies should also include a question that evaluates the expectations that recreationists have before snorkeling or diving regarding pollution levels, crowding levels, and natural environment conditions. Previous studies have tried to analyze the perceptions of management success in Florida Keys National Marine Sanctuary (Quenée, 2019). Managing a marine protected area such as the Florida Keys involve multiple challenges, thus it is important to recognize that good management also depends on the availability of enough funding, staff, research, among others. A marine protected area that has used social sciences to create new policies in their management is Fernando de Noronha Marine National Park in Brazil. Research on carrying capacity has been used to establish laws and policies to manage the marine touristic activities in this island in a sustainable way (Luiz Jr, 2009). Social science insights can be used to aid reef management strategies and increase the potential for actives such as snorkeling and scuba diving to contribute towards reef conservation (Dearden et al., 2006). 


\section{References}

Alessa, L., Bennett, S. M., \& Kliskey, A. D. (2003). Effects of knowledge, personal attribution and perception of ecosystem health on depreciative behaviors in the intertidal zone of Pacific Rim National Park and Reserve. Journal of Environmental Management, 68(2), 207-218.

Anderson, L. E., \& Loomis, D. K. (2011). Scuba diver specialization and behavior norms at coral reefs. Coastal Management, 39(5), 478-491.

Anderson, L.E. \& Loomis, D.K. (2012). Normative standards for coral reef conditions: a comparison of SCUBA divers by specialization level. Journal of Leisure Research, 44, 257-274.

Andrew, R. G., Burns, R. C., Schwarzmann, D., Allen, M. E., \& Moreira, J. C. (2021). Blue Water Visitor Monitoring Potential: A Literature Review and Alternative Proposal. Water, 13(3), 305.

Burns, R. C., Andrew, R. G., Allen, M. E., Schwarzmann, D., \& Cardozo Moreira, J. (2020a). Conceptualizing the National marine sanctuary visitor counting process for marine protected areas. Journal of Ecotourism, 19(4), 362-372.

Burns, R. C., Chuprinko, T., \& Allen, M. E. (2020b). Understanding Pacific Northwest (US) mountain climbers' motivations: Mount Baker, Washington, and Mount Hood, Oregon. Journal on Protected Mountain Areas Research and Management, 12, 4-14.

Burns, Robert C., Allen, M. E., \& Chuprinko, T. L. (2021). Crowding Perceptions at Wilderness Areas on Mount Baker, Washington and Mount Hood, Oregon. International Journal of Wilderness, 27(2).

Burns, R. C., Popham, A. R., \& Smaldone, D. (2018). Examining Satisfaction and Crowding in a Remote, Low Use Wilderness Setting: The Wenaha Wild and Scenic River Case Study. Int. J. Wilderness, 24(3).

Buckley, R. (2003) Environmental Inputs and Outputs in Ecotourism: Geotourism with a Positive Triple Bottom Line?, Journal of Ecotourism, 2:1, 76-82, DOI: 10.1080/14724040308668135

Buckley, R. (2012). Rush as a key motivation in skilled adventure tourism: Resolving the risk recreation paradox. Tourism management, 33(4), 961-970.

Camp, E., \& Fraser, D. (2012). Influence of conservation education dive briefings as a management tool on the timing and nature of recreational SCUBA diving impacts on coral reefs. Ocean \& coastal management, $61,30-37$.

Coghlan, A. (2012). Facilitating reef tourism management through an innovative importance-performance analysis method. Tourism Management, 33(4), 767-775.

da Costa Cristiano, S., Rockett, G. C., Portz, L. C., \& de Souza Filho, J. R. (2020). Beach landscape management as a sustainable tourism resource in Fernando de Noronha Island (Brazil). Marine pollution bulletin, 150, 110621 .

Day, J. (2008). The need and practice of monitoring, evaluating and adapting marine planning and managementlessons from the Great Barrier Reef. Marine policy, 32(5), 823-831.

Dearden, P., Bennett, M., \& Rollins, R. (2006). Implications for coral reef conservation of diver specialization. Environmental Conservation, 33(4), 353-363. 
Deng, W. (2007). Using a revised importance-performance analysis approach: The case of Taiwanese hot springs tourism. Tourism Management, 28(5), 1274-1284.

Dillman, D. A., \& Bowker, D.K. (2001). The web questionnaire challenge to survey methodologists 2001, 53-71.

Dwyer, L., Dragićević, V., Armenski, T., Mihalič, T., \& Knežević Cvelbar, L. (2016). Achieving destination competitiveness: an importance-performance analysis of Serbia. Current Issues in Tourism, 19(13), 1309-1336.

El-Naggar, H. A. (2020). Human Impacts on Coral Reef Ecosystem. In Natural Resources Management and Biological Sciences. IntechOpen.

Fiore, F., Siena, F., Saponari, L., Galli, P., \& Montano, S. (2020). Users' satisfaction on coral restoration projects: The case of the Maldives. Regional Studies in Marine Science, 38, 101369.

Fitzsimmons, C. (2008). Why dive? And why here?: a study of recreational diver enjoyment at a Fijian eco-tourist resort. Tourism in Marine Environments, 5(2-3), 159-173.

Flinzberger, L., Zinngrebe, Y., \& Plieninger, T. (2020). Labelling in Mediterranean agroforestry landscapes: a Delphi study on relevant sustainability indicators. Sustainability Science, 15(5), 1369-1382.

Guadagnolo, F. (1985). The importance-performance analysis: An evaluation and marketing tool. Journal of park and recreation administration, $3(2)$.

Guizzardi, A., \& Stacchini, A. (2017). Destinations strategic groups via multivariate competition-based IPA. Tourism Management, 58, 40-50.

Hansen, A.S. (2015). Monitoring and managing outdoor recreation in coastal and marine areas - what do we know and what do we need to know? Documentation from a Nordic workshop. Unit for Human Geography, University of Gothenburg, 79 p.

Harris, P. T., Westerveld, L., Nyberg, B., Maes, T., Macmillan-Lawler, M., \& Appelquist, L. R. (2021). Exposure of coastal environments to river-sourced plastic pollution. Science of The Total Environment, 769, 145222.

Krieger, J. R., \& Chadwick, N. E. (2013). Recreational diving impacts and the use of pre-dive briefings as a management strategy on Florida coral reefs. Journal of Coastal Conservation, 17(1), 179-189.

Luiz Jr, Osmar. (2009). Estudo de Capacidade de Carga e de Operacionalização das Atividades de Turismo Náutico no Parque Nacional Marinho de Fernando de Noronha. In Projeto para a conservacao e manejo dos ecossistemas brasileiros - PROECOS Projeto PNUD BRA/00/009. UNDP: Brasilia, Brazil, 2009.

Martilla, J. A., \& James, J. C. (1977). Importance-performance analysis. Journal of marketing, 41(1), 77-79.

Mimbs, B. P., Boley, B. B., Bowker, J. M., Woosnam, K. M., \& Green, G. T. (2020). Importance-performance analysis of residents' and tourists' preferences for water-based recreation in the Southeastern United States. Journal of Outdoor Recreation and Tourism, 31, 100324.

NOAA. (2021). About Florida Keys National Marine Sanctuary. Retrieved from https://floridakeys.noaa.gov/about/welcome.html?s=about

NOAA. (2021). What is a national marine sanctuary? Retrieved from https://oceanservice.noaa.gov/facts/nms.html. 
NMSA. (1992). National Marine Sanctuaries Act Agencies: 16 U.S.C. §§ 1431 et seq.

Oh, H. (2001). Revisiting importance-performance analysis. Tourism management, 22(6), 617-627.

Oigman-Pszczol, S. S., Oliveira, A. E. S., \& Creed, J. C. (2007). Perceptions of coral in a coastal tourist town in Brazil. Coral Reefs, 26(3), 667-670.

Paterson, S., Young, S., Loomis, D. K., \& Obenour, W. (2012). Resource attributes that contribute to nonresident diver satisfaction in the Florida Keys, USA. Tourism in Marine Environments, 8(1-2), 47-60.

Priskin, J. (2003). Tourist perceptions of degradation caused by coastal nature-based recreation. Environmental management, 32(2), 189-204.

Quenée, C. T. (2019). Perception of Management Success in the Florida Keys National Marine Sanctuary: A Comparative Analysis Between Residents and Visitors. Perception, 2019, 12-12.

Rossier, R. (1995). What is visibility? Illuminating facts about an unclear situation. Dive Training Magazine. Retrieved from https://dtmag.com/thelibrary/visibility-illuminating-facts-unclear-situation/

Shivlani, M. P., \& Suman, D. O. (2000). Dive operator use patterns in the designated no-take zones of the Florida Keys National Marine Sanctuary (FKNMS). Environmental Management, 25(6), 647-659.

Stafford, R., \& Jones, P. J. (2019). Viewpoint-Ocean plastic pollution: A convenient but distracting truth?. Marine policy, 103, 187-191.

UNEP. (2018). The Global Programme of Action for the Protection of the Marine Environment from Land-Based Activities. A 20-year Perspective on a Unique Programme to Advance the Ocean Agenda.

UNESCO. (2005). Sustainable Tourism Development in UNESCO Designated Sites in South-Eastern Europe. Ecological Tourism in Europe-ETE, 1-43.

Ursi, S., \& Towata, N. (2018). Environmental Perception About Marine and Coastal Ecosystems: Evaluation Through A Research Instrument Based on Model of Ecological Values. Problems of education in the 21st century, 76(3).

Uyarra, M., Watkinson, A., \& Cote, I. M. (2009). Managing dive tourism for the sustainable use of coral reefs: Validating diver perceptions of attractive site features. Environmental Management, 43(1), 1-16.

van Riper, C. J., Lum, C., Kyle, G. T., Wallen, K. E., Absher, J., \& Landon, A. C. (2020). Values, motivations, and intentions to engage in proenvironmental behavior. Environment and Behavior, 52(4), 437-462.

von Ruschkowski, E.; Burns, R.; Arnberger, A.; Smaldone, D.; Meybin, J. Recreation Management in Parks and Protected Areas: A Comparative Study of Resource Managers Perceptions in Austria, Germany, and the United States. Journal of Park and Recreation Administration 2013, 31, 95-114.

Winter, P. L., Selin, S., Cerveny, L., \& Bricker, K. (2020a). Outdoor recreation, nature-based tourism, and sustainability. Sustainability, 12(1), 81 .

Winter, P. L., Crano, W. D., Basáñez, T., \& Lamb, C. S. (2020b). Equity in access to outdoor recreation-informing a sustainable future. Sustainability (Switzerland), 12(1), 1-16. https://doi.org/10.3390/SU12010124 
Wynveen, C. J., Connally, W. D., \& Kyle, G. T. (2013). Pro-environmental behavior in marine protected areas: the cases of the Great Barrier Reef Marine Park and the Florida Keys National Marine Sanctuary. Journal of Park and Recreation Administration, 31(2).

Wynveen, C. J., Wynveen, B. J., \& Sutton, S. G. (2015). Applying the value-belief-norm theory to marine contexts: Implications for encouraging pro-environmental behavior. Coastal Management, 43(1), 84-103.

Ziegler, J., Dearden, P., \& Rollins, R. (2012). But are tourists satisfied? Importance-performance analysis of the whale shark tourism industry on Isla Holbox, Mexico. Tourism Management, 33(3), 692-701. 


\section{Conclusion}

This research helped us to successfully understand more about the visitor use that occurs in Florida Keys National Marine Sanctuary. The results of both papers showed us that minority populations are underrepresented in the public that recreates in the Sanctuary. On one hand, the current visitor profile (i.e. middle-aged, well-educated and affluent white male) is brining significant economic contributions to the local businesses. On the other hand, the expenditures that a visitor spends on a typical trip for ocean recreation might be too high and unaffordable for people with low household incomes. It is suggested that managers in the Sanctuary create and implement strategies to improve the accessibility in order to provide recreational opportunities for the minorities. Providing equitable recreation opportunities can be greatly beneficial for all the stakeholders involved and especially for the conservation of the Sanctuary.

User satisfaction levels in the Sanctuary were reported as high. As it was mentioned earlier, multiple variables can influence visitor satisfaction. Experiencing natural surroundings was a significant predictor item that showed a positive relationship to satisfaction in this study. Crowding levels reported by the users were low therefore, managers should not consider crowding as an issue now. However, it should be a point of attention in order to avoid increases in crowding levels in the future thus, constant monitoring is needed. The results of this thesis are valuable since previous research related to satisfaction and crowding has been traditionally focused on terrestrial and not on marine settings. Snorkelers and scuba divers in the Sanctuary may seek feelings of solitude as an important component of their underwater recreational experience. More experienced and specialized snorkelers and divers can hold stronger preferences for the number of people they observe in the setting and may be less tolerant than novice first-time visitors. This thesis can help define carrying capacity for social thresholds in 
the Sanctuary. it is important to acknowledge the critical connection that human dimensions have in marine natural resources. On one hand, studying social crowding while snorkeling or diving can be a significant indicator of the pressures that are created in the biodiverse ecosystems that are living underwater. On the other hand, satisfaction of snorkelers of snorkelers and scuba divers can be a critical indicator for the economic contribution that outdoor recreation is making in the local socioeconomic development of the area.

This thesis also examined the importance and performance levels of recreationists and managers' environmental perceptions. Different people might have different reactions to the same environment; therefore, environmental values and attitudes are an important part of environmental perceptions. This is an extremely important aspect from the management perspective since the visitors' values, attitudes and behaviors can heavily impact the natural marine resources, whether that is in a positive or negative way. It is likely that the recreationists and managers in this study are distributed on a biocentric to an anthropocentric continuum. This placement allows them to have different environmental perceptions. The IPA technique facilitates the development of strategies for managers without being versed in complicated statistical analysis. Overall, recreationists think that managers should keep up the good work in the Sanctuary. Recreationists were slightly more satisfied than managers in the majority of the items except for experiencing good underwater clarity and the availability of an open mooring buoy. Environmental education and interpretive methods including pre-dive ecological briefings can provide positive effects on the visitors' behavior and give them a clearer idea of what to expect during their recreational experience. Coral reefs are one of the main attractions in this tourism destination therefore, seeing a healthy reef, experiencing a clean reef and diving on an area free of trash should be a management priority for the local managers. The importance- 
performance grids were useful to identify where the managers should concentrate on, what are the items to keep up the good work, the items that are low priority and the possible overkills.

It is important to recognize that the complexity of monitoring visitor for managers use include challenges such as lack of funding, staff and other resources. Therefore, finding ways to facilitate visitor use monitoring can include data collection methods that are cost-effective such as online questionnaires instead of in-person interviews. Understanding visitation characteristics are the first steps to accurately estimate the associated benefits and economic contributions. Social science insights can be used to aid management strategies and increase the potential for activities such as snorkeling and scuba diving to contribute toward reef conservation. Finally, it is likely that managers in marine protected areas focus high levels of their research attention in natural sciences, however, this thesis emphasizes the importance of social sciences to better manage national marine sanctuaries in a way that is sustainable and ecologically balanced. 


\section{Appendix A: Survey Instrument 1}

This is the Basic Survey of Scuba Divers and Snorkelers in Florida Keys National Marine Sanctuary. If you are willing to participate in our survey, please tell us some info about yourself and your activities around FKNMS. All questions and answers are optional and voluntary. The information collected will help resource managers better understand visitation in FKNMS and surrounding area. This survey is supported by the National Marine Sanctuary Foundation and the Monroe County Tourism Development Council.

1. Do you primarily consider yourself a snorkeler or a SCUBA diver?

1) Snorkeler

2) SCUBA diver

2. As a SCUBA diver, what is the highest level of certification you presently hold?

1) None - I am not a SCUBA diver

2) Open Water

3) Advanced Open Water

4) Rescue

5) Dive Master

6) Instructor

7) Other (please specify):

3. Are you certified in any dive specialties? (Example: Nitrox, Project Aware, Coral Reef Conservation, etc.) If so, please list:

4. In what year did you first go snorkeling and/or SCUBA diving? Year I first went Snorkeling Year I first went SCUBA Diving

5. During the 2019 calendar year, how many days did you snorkel and/or SCUBA dive in the Florida Keys?

Number of days Snorkeling Number of days SCUBA Diving

6. Since your first visit to the Florida Keys until the end of the 2019 calendar year, has the amount you visit the Florida Keys changed over time?

1) I have only ever visited the Florida Keys once

2) Far fewer visits

3) Fewer visits

4) Remained about the same

5) More visits

6) Many more visits

7) N/A - Not Applicable (I'm a resident of the Florida Keys) 
7. Consider the total amount of time you spend snorkeling and SCUBA diving in general, regardless of location. Between the two, what percentage of time to you spend snorkeling versus SCUBA diving? (Please note the two should total to 100\%.)

Percent of time Snorkeling

Percent of time SCUBA Diving

8. How many people (including yourself) are typically in your group for the following ocean recreation activities on a typical trip?

\# People Snorkeling

\# People SCUBA Diving

9. On your most recent 2019 trip to the Florida Keys, which types of sites did you use for snorkeling and SCUBA diving? Please select all that apply.

Beach

Coral Reefs

Seagrass beds

Shipwrecks

Other

10. Consider all of the time you spent in the Florida Keys during the 2019 calendar year. What percent of the time did you participate in recreation activities at each of the following types of locations? (Please note, the total should amount to 100\%.)

Beach

Coral Reefs

Seagrass beds

Shipwrecks

Other

TOTAL

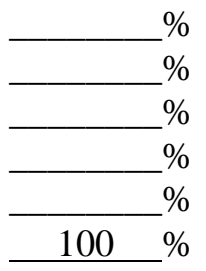

11. Consider your most recent 2019 snorkeling or SCUBA diving trip to the Florida Keys. Overall, how satisfied were you with your experience? ( 1 is not at all satisfied and 10 is extremely satisfied) Satisfaction Level:

12. If you use a recreational outfitter-guide when you visit the Florida Keys for activities (charter fishing, SCUBA diving, etc.) please list up to the top 3 most common businesses/outfitters you would use. (If you do not use outfitter-guides, please mark " $x$ " in the N/A - Not Applicable area)

Outfitter-Guide 1

Outfitter-Guide 2

Outfitter-Guide 3

N/A - Not Applicable 
13. When you decide to make a trip to snorkel or SCUBA dive in the Florida Keys, how important are the following factors?

a. Experiencing a pristine environment
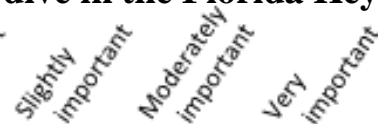

b. Avoiding crowds

.1

c. Doing my part to protect natural resources

2

2

d. Learning about the ocean

1

e. Improving my skills

14. On the following map image, please click the location that you most frequently depart from to travel into the ocean for recreation.

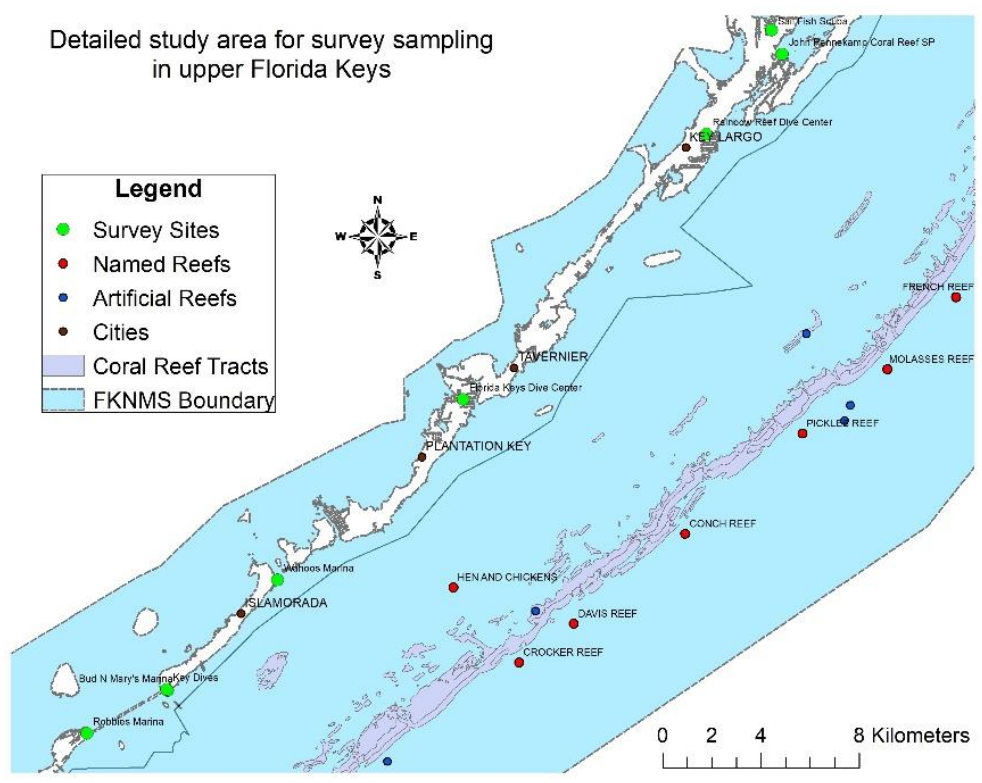

15. On the following map image, please click the location that you most visit for ocean recreation within the area shown.

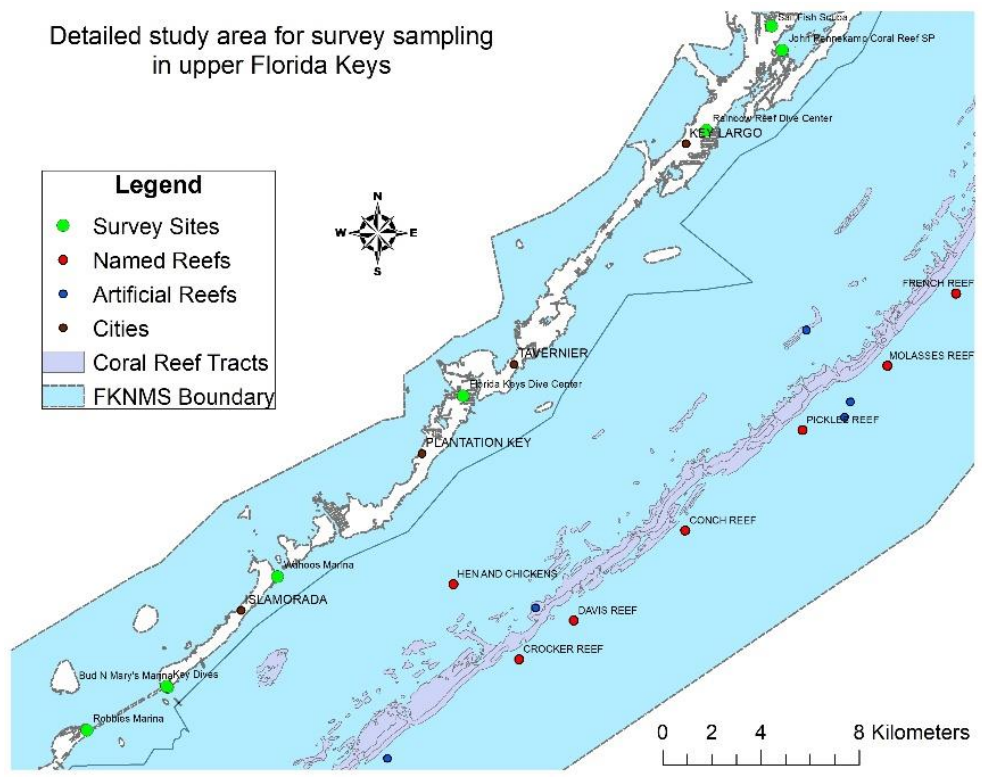


16. On your most recent 2019 snorkeling/SCUBA diving trip to a coral reef in the Florida Keys, how did the number of people you saw compare with what you expected to see?

1) A lot less than you expected

2) A little less than you expected

3) About what you expected

4) A little more than you expected

5) A lot more than you expected

6) You didn't have any expectations

17. How crowded did you feel while actively snorkeling or diving during your most recent 2019 trip in the Florida Keys? (1 is Not at all crowded and 9 is Extremely crowded)

Crowding Level:

The Blue Star Diving program was created by the Florida Keys National Marine Sanctuary. We are interested in your awareness of the program and its role in your trip planning.

18. On your most recent dive/snorkel trip in 2019, were you told about the Blue Star Program?

1) Yes

2) No

3) I don't know

19. Please rate the extent to which you agree or disagree with the following statements about the Blue Star Program.

\begin{tabular}{|l|l|l|l|l|l|}
\hline & $\begin{array}{c}\text { Strongly } \\
\text { Disagree }\end{array}$ & $\begin{array}{c}\text { Somewhat } \\
\text { Disagree }\end{array}$ & $\begin{array}{c}\text { Neither Agree } \\
\text { nor Disagree }\end{array}$ & $\begin{array}{c}\text { Somewhat } \\
\text { Agree }\end{array}$ & $\begin{array}{c}\text { Strongly } \\
\text { Agree }\end{array}$ \\
\hline $\begin{array}{l}\text { I am familiar with the mission of the Blue Star } \\
\text { Program }\end{array}$ & & & & & \\
\hline $\begin{array}{l}\text { A dive shop's participation in the Blue Star } \\
\text { Program affects my decision to book a trip } \\
\text { with them }\end{array}$ & & & & & \\
\hline $\begin{array}{l}\text { Blue Star-certified dive shops provide a more } \\
\text { superior experience compared to non-Blue } \\
\text { Star-certified dive shops }\end{array}$ & & & & & \\
\hline $\begin{array}{l}\text { I am more likely to book repeat trips with dive } \\
\text { shops that are Blue Star-certified }\end{array}$ & & & & & \\
\hline
\end{tabular}

This section asks you about your perceptions of coral reef conditions based on your snorkeling and/or diving experience in the Florida Keys.

20. Overall, how would you rate the health of the coral reef ecosystems in the Florida Keys in 2019? ( 1 is extremely poor and 10 is excellent)

Level of Current Health of Coral Reef Ecosystems: 
21. Do you feel that the health of coral reef ecosystems in the Florida Keys are improving, declining, or staying the same?

1) Declining substantially

2) Declining somewhat

3) Staying the same

4) Improving somewhat

5) Improving substantially

22. Overall, do you feel the following are having a positive or negative impact on the ecological health of marine resources in the Florida Keys? (1 being Extremely Negative Impact and 5 being Extremely Positive Impact)
a. SCUBA diving
b. Snorkeling
c. Commercial fishing
d. Hurricanes
e. Boating
f. Recreational fishing
g. Global climate change
h. Development activities in South Florida
i. Marine debris/trash

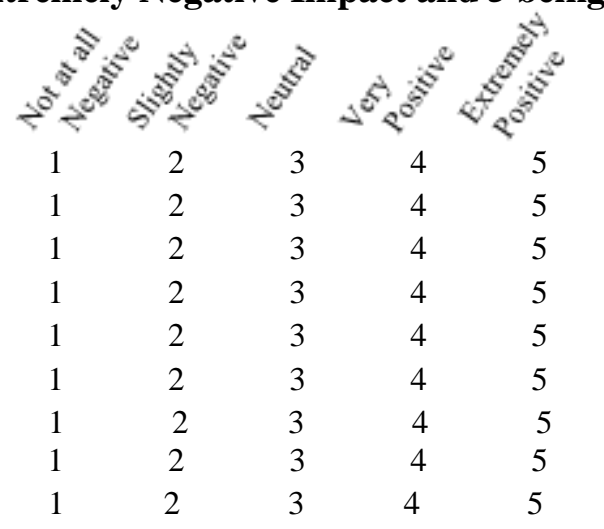

23. Please indicate if you would agree or disagree that coral restoration in the Florida Keys helps to:

\begin{tabular}{|l|l|l|l|l|l|}
\hline & $\begin{array}{c}\text { Strongly } \\
\text { Disagree }\end{array}$ & $\begin{array}{c}\text { Somewhat } \\
\text { Disagree }\end{array}$ & $\begin{array}{c}\text { Neither Agree } \\
\text { nor Disagree }\end{array}$ & $\begin{array}{c}\text { Somewhat } \\
\text { Agree }\end{array}$ & $\begin{array}{c}\text { Strongly } \\
\text { Agree }\end{array}$ \\
\hline Improve the overall health of the reef & & & & & \\
\hline Increase the number of fish species in the area & & & & & \\
\hline Enhance the SCUBA diving experience & & & & & \\
\hline Enhance the level of biological knowledge & & & & & \\
\hline Improve the local economy & & & & & \\
\hline
\end{tabular}

24. Below is a list of characteristics that you may notice while snorkeling/SCUBA diving. Consider your most recent snorkeling/SCUBA diving experience in the Florida Keys in 2019 and rate the condition of the characteristics for each of the following items.

\begin{tabular}{|l|l|l|l|l|l|}
\hline & $\begin{array}{c}\text { Extremely } \\
\text { bad }\end{array}$ & $\begin{array}{c}\text { Somewhat } \\
\text { bad }\end{array}$ & $\begin{array}{c}\text { Neither good } \\
\text { nor bad }\end{array}$ & $\begin{array}{c}\text { Somewhat } \\
\text { good }\end{array}$ & $\begin{array}{c}\text { Extremely } \\
\text { good }\end{array}$ \\
\hline Amount of algae present & & & & & \\
\hline Underwater visibility & & & & & \\
\hline Color of the coral & & & & & \\
\hline Number of fish & & & & & \\
\hline Amount of live coral & & & & & \\
\hline
\end{tabular}


25. During a typical snorkeling trip or dive trip in the Florida keys, how acceptable or unacceptable do you consider each of the following marine resource conditions to be?

\begin{tabular}{|l|l|l|l|l|l|}
\hline & $\begin{array}{l}\text { Strongly } \\
\text { Unacceptable }\end{array}$ & $\begin{array}{c}\text { Moderately } \\
\text { Unacceptable }\end{array}$ & Neutral & $\begin{array}{c}\text { Moderately } \\
\text { Acceptable }\end{array}$ & $\begin{array}{c}\text { Strongly } \\
\text { Acceptable }\end{array}$ \\
\hline Coral reefs that are mostly white & & & & & \\
\hline $\begin{array}{l}\text { Coral reefs that are } 60 \% \text { mostly } \\
\text { white }\end{array}$ & & & & & \\
\hline $\begin{array}{l}\text { Coral reefs that are 30\% mostly } \\
\text { white }\end{array}$ & & & & & \\
\hline $\begin{array}{l}\text { Coral reefs with no white } \\
\text { present }\end{array}$ & & & & & \\
\hline
\end{tabular}

26. How important was it to you to do each of the following during your most recent 2019 trip to the Florida Keys

a. To see a healthy reef

b. To dive in an uncrowded area

c. To experience good underwater clarity

d. To experience natural surroundings

e. To experience adventure

f. To leave the reef cleaner than you found it

g. To be able to use a mooring buoy

h. To dive on an area free of discarded fish traps, fishing line

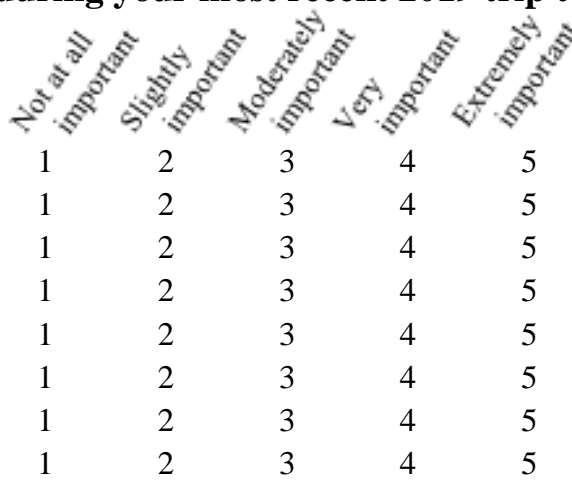

\section{How satisfied were you with each of the following during your more recent trip to the Florida} Keys? (1 being Not at all Satisfied and 5 being Extremely Satisfied)

a. Seeing a healthy reef

b. Diving in an uncrowded area

c. Experiencing good underwater clarity

d. Experiencing natural surroundings

e. Experiencing adventure

f. Experiencing a clean reef

g. Availability of an open mooring buoy

g. Diving on an area that is free of discarded fish traps, fishing line

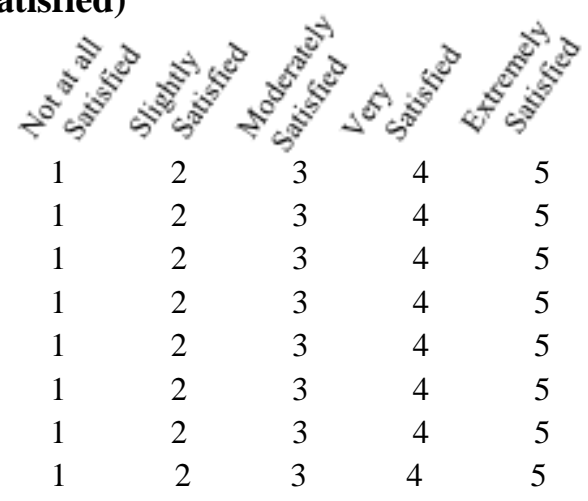

The following questions are meant to collect demographic data about you. These data will be collected and used in a similar manner as U.S. Census data, and will never be shared or used outside of this research project.

28. Are you a:

Permanent Resident of Monroe County, FL

Seasonal Resident of Monroe County, FL

Visitor 
29. What is your home (primary residence) ZIP code?

or not from US/Canada (Location:)

23. What is your age?

24. What is your gender? ___ Male __ Female

25. Would you classify yourself as Hispanic or Latino? Yes No

26. Which category best describes your race? (Please choose any that apply) American Indian or Alaskan Native Asian Black or African American Native Hawaiian or other Pacific Islander White Other

27. What is the highest grade of school you have completed? (please check one) Grade school Some college Post graduate High school graduate/GED equivalent College graduate

28. Which of the following categories best describes your annual household income Under $\$ 25,000$ $\$ 25,001-\$ 50,000$ $\$ 50,001-\$ 75,000$ $\$ 75,001$ - $\$ 100,000$ $\$ 100,001-\$ 150,000$ Over $\$ 150,000$

29. Is there anything else about SCUBA diving or snorkeling in the Florida Keys or this questionnaire that you would like to share with us?

Thank you for participating in this survey research which will help inform resource managers! 


\section{Appendix B: Survey Instrument 2}

This is the Economic Survey of Scuba Divers and Snorkelers in Florida Keys National Marine Sanctuary. If you are willing to participate in our survey, please tell us some info about yourself and your activities around FKNMS. All questions and answers are optional and voluntary. The information collected will help resource managers better understand visitation in FKNMS and surrounding area. This survey is supported by the National Marine Sanctuary Foundation and the Monroe County Tourism Development Council.

1. Do you primarily consider yourself a snorkeler or a SCUBA diver?

1) Snorkeler

2) SCUBA diver

2. As a SCUBA diver, what is the highest level of certification you presently hold?

1) None - I am not a SCUBA diver

2) Open Water

3) Advanced Open Water

4) Rescue

5) Dive Master

6) Instructor

7) Other (please specify):

3. Are you certified in any dive specialties? (Example: Nitrox, Project Aware, Coral Reef Conservation, etc.) If so, please list:

4. In what year did you first go snorkeling and/or SCUBA diving? Year I first went Snorkeling Year I first went SCUBA Diving

5. During the 2019 calendar year, how many days did you snorkel and/or SCUBA dive in the Florida Keys? Number of days Snorkeling Number of days SCUBA Diving

6. Since your first visit to the Florida Keys until the end of the 2019 calendar year, has the amount you visit the Florida Keys changed over time?

1) I have only ever visited the Florida Keys once

2) Far fewer visits

3) Fewer visits

4) Remained about the same

5) More visits 
6) Many more visits

7) N/A - Not Applicable (I'm a resident of the Florida Keys)

7. Consider the total amount of time you spend snorkeling and SCUBA diving in general, regardless of location. Between the two, what percentage of time to you spend snorkeling versus SCUBA diving? (Please note the two should total to 100\%.)

Percent of time Snorkeling

Percent of time SCUBA Diving

8. How many people (including yourself) are typically in your group for the following ocean recreation activities on a typical trip?

\# People Snorkeling

\# People SCUBA Diving

9. On your most recent 2019 trip to the Florida Keys, which types of sites did you use for snorkeling and SCUBA diving? Please select all that apply.

Beach

Coral Reefs

Seagrass beds

Shipwrecks

Other

10. Consider all of the time you spent in the Florida Keys during the 2019 calendar year. What percent of the time did you participate in recreation activities at each of the following types of locations? (Please note, the total should amount to 100\%.)

Beach

Coral Reefs

Seagrass beds

Shipwrecks

Other

TOTAL

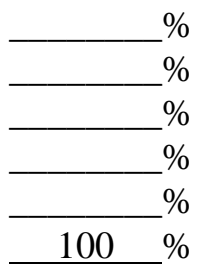

11. Consider your most recent 2019 snorkeling or SCUBA diving trip to the Florida Keys. Overall, how satisfied were you with your experience? ( 1 is not at all satisfied and 10 is extremely satisfied) Satisfaction Level:

12. If you use a recreational outfitter-guide when you visit the Florida Keys for activities (charter fishing, SCUBA diving, etc.) please list up to the top 3 most common businesses/outfitters you would use. (If you do not use outfitter-guides, please mark " $x$ " in the N/A - Not Applicable area)

Outfitter-Guide 1

Outfitter-Guide 2

Outfitter-Guide 3

N/A - Not Applicable 
13. On the following map image, please click the location that you most frequently depart from to travel into the ocean for recreation.

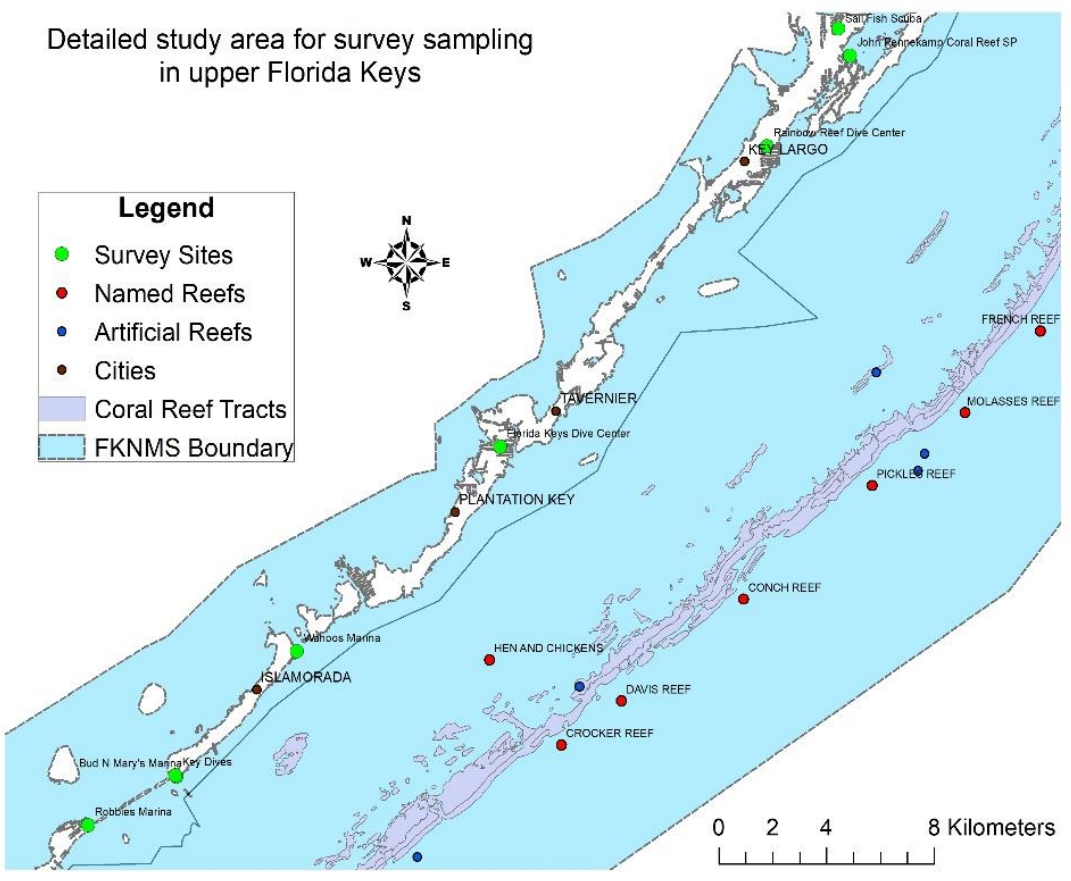

14. On the following map image, please click the location that you most visit for ocean recreation within the area shown.

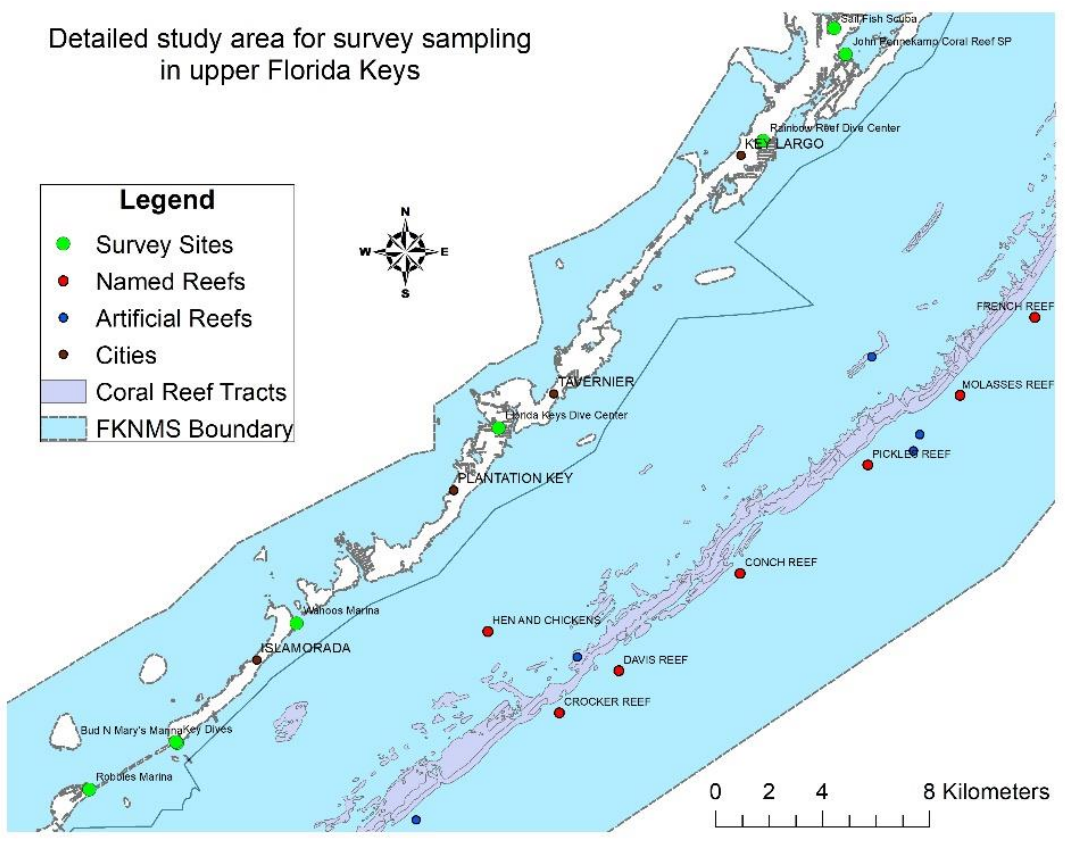

15. On your most recent 2019 snorkeling/SCUBA diving trip to a coral reef in the Florida Keys, how did the number of people you saw compare with what you expected to see?

1) A lot less than you expected

2) A little less than you expected 
3) About what you expected

4) A little more than you expected

5) A lot more than you expected

6) You didn't have any expectations

16. How crowded did you feel while actively snorkeling or diving during your most recent 2019 trip in the Florida Keys? ( 1 is Not at all crowded and 9 is Extremely crowded)

Crowding Level:

The Blue Star Diving program was created by the Florida Keys National Marine Sanctuary. We are interested in your awareness of the program and its role in your trip planning.

17. On your most recent dive/snorkel trip in 2019, were you told about the Blue Star Program?

1) Yes

2) No

3) I don't know

18. Please rate the extent to which you agree or disagree with the following statements about the Blue Star Program.

\begin{tabular}{|l|l|l|l|l|l|}
\hline & $\begin{array}{c}\text { Strongly } \\
\text { Disagree }\end{array}$ & $\begin{array}{c}\text { Somewhat } \\
\text { Disagree }\end{array}$ & $\begin{array}{c}\text { Neither Agree } \\
\text { nor Disagree }\end{array}$ & $\begin{array}{c}\text { Somewhat } \\
\text { Agree }\end{array}$ & $\begin{array}{c}\text { Strongly } \\
\text { Agree }\end{array}$ \\
\hline $\begin{array}{l}\text { I am familiar with the mission of the Blue Star } \\
\text { Program }\end{array}$ & & & & & \\
\hline $\begin{array}{l}\text { A dive shop's participation in the Blue Star } \\
\text { Program affects my decision to book a trip } \\
\text { with them }\end{array}$ & & & & & \\
\hline $\begin{array}{l}\text { Blue Star-certified dive shops provide a more } \\
\text { superior experience compared to non-Blue } \\
\text { Star-certified dive shops }\end{array}$ & & & & & \\
\hline $\begin{array}{l}\text { I am more likely to book repeat trips with dive } \\
\text { shops that are Blue Star-certified }\end{array}$ & & & & & \\
\hline
\end{tabular}

This section asks you about other activities and experiences related to your recent trip to the Florida Keys in 2019.

19. Besides snorkeling and/or SCUBA diving, what activities did you participate in during your visit in the Florida Keys? Select all that apply.

Fishing

_Hiking

_Biking

_Birding or other nature-viewing

_Camping

_Picnicking

__Paddle boarding, kayaking, canoeing, paddle sports

_Boating

_Florida Keys Welcome Centers

_Public event (festival, concert, etc.)

_Private event (wedding, conference, etc.) 
Other activities in Key Largo area (please specify)

_Other activities in Islamorada area (please specify)

20. In 2019, visiting the Florida Keys for snorkeling and/or SCUBA diving was the: [check one]

1) Only purpose of my trip(s)

2) Primary purpose of my trip(s)

3) One of the many stops on my trip(s)

21. Out of all the time I spend snorkeling and/or SCUBA diving in the Florida Keys, I typically access dive sites/locations by the following methods at the following percentage of the time: Please note, the total should add to $100 \%$.

Public access points from shore

Private access points from shore

Rental boat to go offshore

Private boat to go offshore

Dive/snorkel tour guide/commercial operator

22. During a typical trip in 2019 to the Florida Keys, approximately how many people were in your group, including yourself?

\# of people including me

23. Please enter your estimated individual spending in the Florida Keys over the entirety of a typical 2019 visit: Please enter a dollar amount for each category below (If you are a resident of the Florida Keys, please enter the approximate amount for a typical 7-day week time period).

\$ Lodging (hotel, condo rental, camping, etc.)

\$ Gift shop items/souvenirs

$\$$ Food at restaurants

$\$$ Food at grocery stores

$\$$ Local fuel expenses (gas/diesel)

\$ Local automobile transportation (Uber, taxi, rental car, etc.)

\$ Sightseeing and entertainment (recreation activities, tours, excursions, museums, etc.)

\$ Rental Equipment for diving/snorkeling (e.g. air tank fills, masks, fins, etc.)

24. Please enter your estimated total individual spending on a typical 2019 trip to the Keys in the following areas: (enter a dollar amount for each location below: (If you are a resident of the Florida Keys, please enter the approximate amount for a typical 7-day week time period).

\$ North Key Largo/Old Rhodes Key

\$ Key Largo

\$ Tavernier/Plantation Key 
\$ Islamorada/Upper Matecumbe Key

\$ Other Location (please list the location)

25. During the 2019 calendar year, estimate your total individual spending on snorkeling and/or SCUBA diving in the Florida Keys for each season. (slide to indicate the approximate amount of individual spending on snorkeling and/or SCUBA diving activities)

\$ Winter (Dec-Feb)

$\$$ Spring (Mar-May)

\$ Summer (Jun-Aug)

\$ Fall (Sep-Nov)

26. In addition to the total amount you pay to go on a single dive/snorkel trip, how much more would you be willing to pay if the additional funds went to the following? (please slide to indicate the additional monetary value, if any)

Coral restoration $\$$

Cleanup of trash/marine debris $\$$

The following questions are meant to collect demographic data about you. These data will be collected and used in a similar manner as U.S. Census data, and will never be shared or used outside of this research project.

27. Are you a:

Permanent Resident of Monroe County, FL

Seasonal Resident of Monroe County, FL

Visitor

28. What is your home (primary residence) ZIP code?

or not from US/Canada (Location:)

29. What is your age?

30.What is your gender? Male Female

31. Would you classify yourself as Hispanic or Latino? Yes No

32. Which category best describes your race? (Please choose any that apply)

American Indian or Alaskan Native

Asian

Black or African American

Native Hawaiian or other Pacific Islander 
White

Other

33. What is the highest grade of school you have completed? (please check one)

Grade school

Some college

Post graduate

High school graduate/GED equivalent

College graduate

34. Which of the following categories best describes your annual household income

Under $\$ 25,000$

$\$ 25,001-\$ 50,00$

$\$ 50,001-\$ 75,000$

$\$ 75,001$ - $\$ 100,000$

$\$ 100,001$ - $\$ 150,000$

Over $\$ 150,000$

35. Is there anything else about SCUBA diving or snorkeling in the Florida Keys or this questionnaire that you would like to share with us?

Thank you for participating in this survey research which will help inform resource managers! 